\title{
Mechano- and Thermo-responsive Luminescence of Crystalline Thienylbenzothiadiazole Derivatives: Stepwise Hypsochromic Switching of Near-Infrared (NIR) Emission
}

Ryohei Yoshida, ${ }^{1}$ Takashi Tachikawa, ${ }^{* 2,3}$ and Suguru Ito*1

${ }^{I}$ Department of Chemistry and Life Science, Graduate School of Engineering Science,

Yokohama National University

79-5 Tokiwadai, Hodogaya-ku, Yokohama 240-8501, Japan

*E-mail: suguru-ito@ynu.ac.jp

${ }^{2}$ Department of Chemistry, Graduate School of Science, Kobe University,

1-1 Rokkodai-cho, Nada-ku, Kobe 657-8501, Japan

${ }^{3}$ Molecular Photoscience Research Center, Kobe University,

1-1 Rokkodai-cho, Nada-ku, Kobe 657-8501, Japan

*E-mail: tachikawa@port.kobe-u.ac.jp

\section{Table of contents}

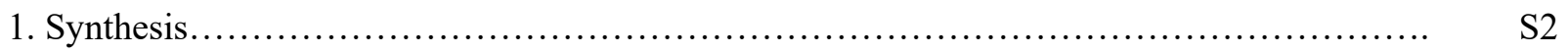

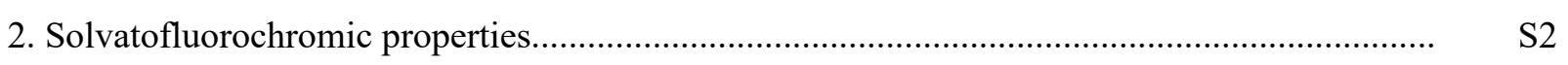

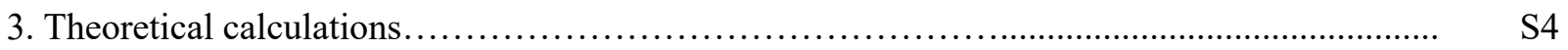

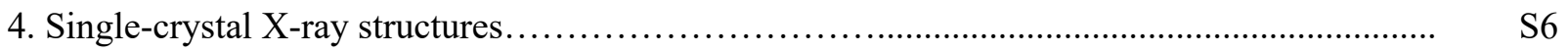

5. Supplementary spectra for the emission switching........................................................... S9

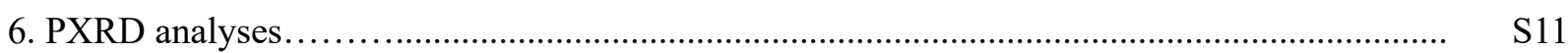

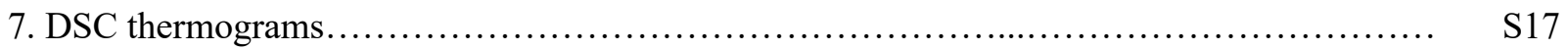

8. Measurements of fluorescence lifetimes................................................ S18

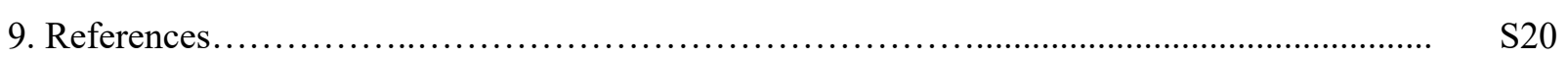

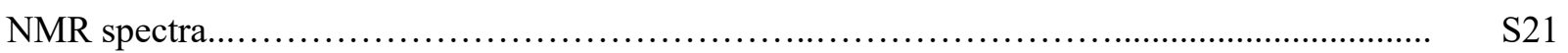




\section{Synthesis}

\section{Synthesis of $\mathbf{1 f}$ and $\mathbf{1 g}$}

The aldehyde $\mathbf{1 f}\left(\mathrm{R}^{1}=n\right.$-Hex, $\left.\mathrm{R}^{2}=\mathrm{CHO}\right)$ and $\mathbf{1 g}\left(\mathrm{R}^{1}=\mathrm{Ph}, \mathrm{R}^{2}=\mathrm{CHO}\right)$ were synthesized through the Suzuki-Miyaura coupling between 4-bromo-7-formylbenzo[c][1,2,5]thiadiazole and the corresponding 2-thienylboronic acid in 74\% and 61\% yield, respectively (Scheme S1).<smiles>[R]c1ccc(Br)s1</smiles>

$\mathrm{R}=n-\mathrm{Hex}$ or $\mathrm{Ph}$

(1.2 equiv.)<smiles>O=Cc1ccc(Br)c2nsnc12</smiles>

N $S^{-N}$

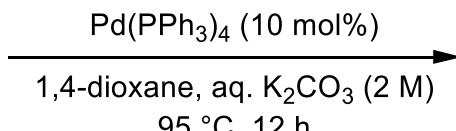

$95^{\circ} \mathrm{C}, 12 \mathrm{~h}$

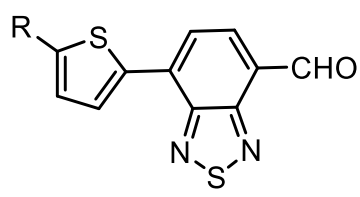

$1 f(\mathrm{R}=n$-Hex $) 74 \%$ $1 \mathrm{~g}(\mathrm{R}=\mathrm{Ph}) \quad 61 \%$

Scheme S1 Synthesis of thienylbenzothiadiazole derivatives $\mathbf{1 f}$ and $\mathbf{1 g}$.

\section{Solvatofluorochromic properties}

The thienylbenzothiadiazole derivatives $1 \mathbf{a}-\mathbf{g}$ showed the solvatofluorochromism in various solvents (hexane, toluene, THF, $\mathrm{CHCl}_{3}$, and DMSO). The emission bands of these derivatives shifted in the bathochromic direction in more polar solvents (Figures S1-S7). All derivatives exhibited good fluorescence quantum yields $\left(\Phi_{\mathrm{F}}\right)$ even in polar solvents, although relatively low $\Phi_{\mathrm{F}}$ values were observed for hexane solutions. Such a tendency is often observed in ICT-based fluorophores. ${ }^{1,2}$

(a)

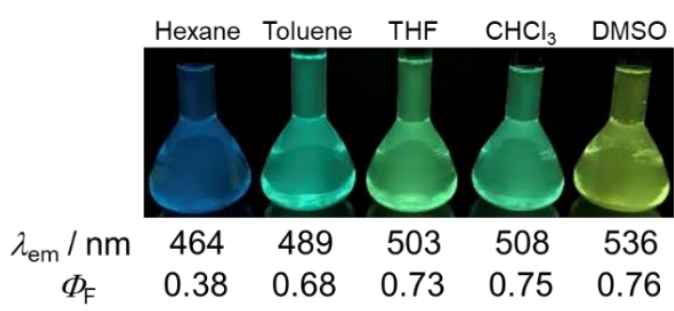

(b)

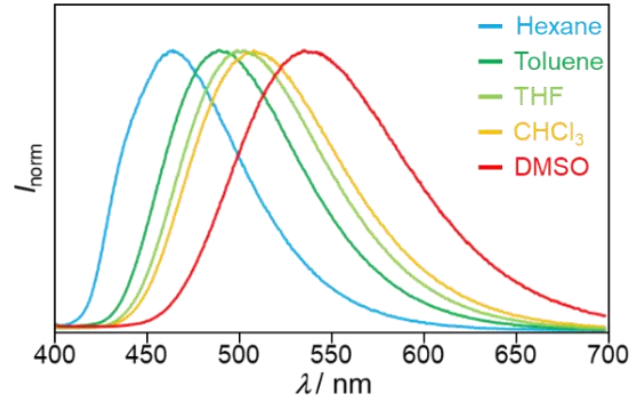

Figure S1 (a) Photographs and (b) emission spectra of solvatofluorochromism of 1a.

(a)

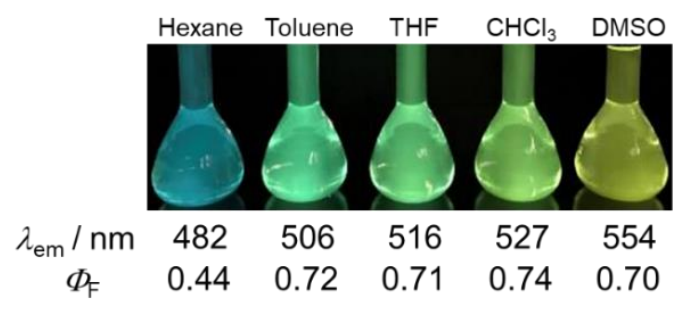

(b)

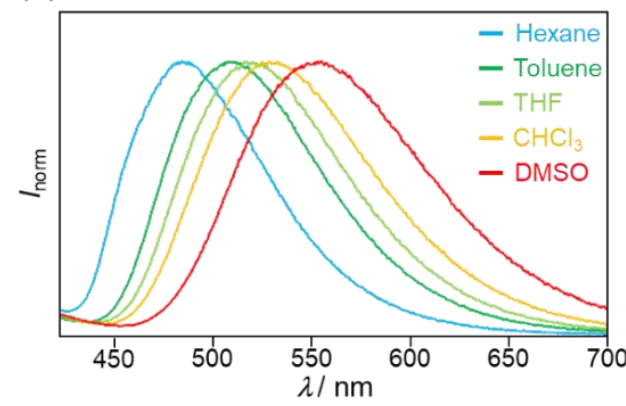

Figure S2 (a) Photographs and (b) emission spectra of solvatofluorochromism of $\mathbf{1 b}$. 
(a)

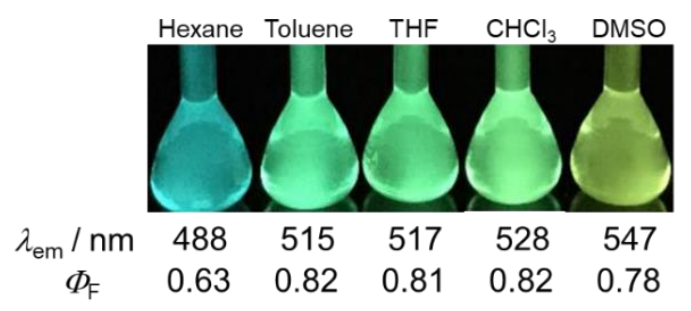

(b)

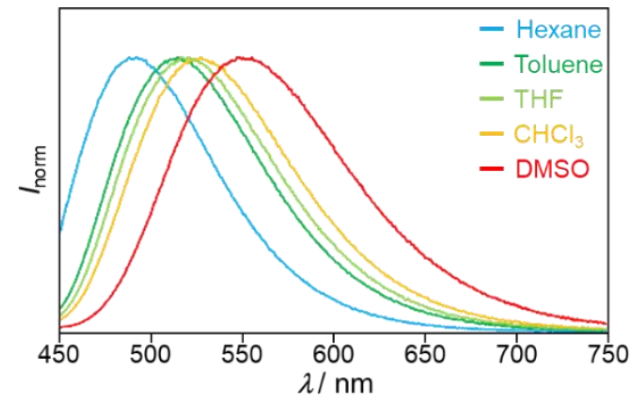

Figure S3 (a) Photographs and (b) emission spectra of solvatofluorochromism of 1c.

(a)

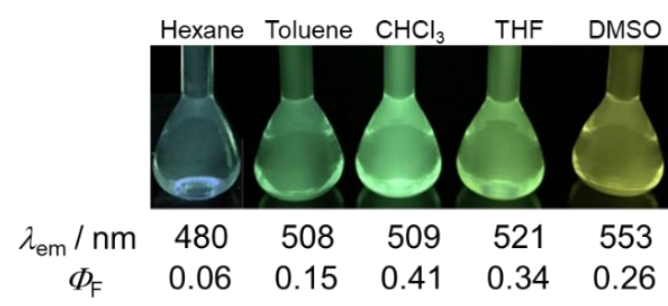

(b)

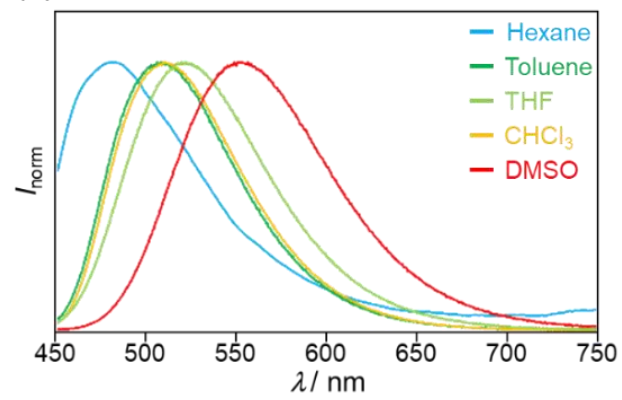

Figure S4 (a) Photographs and (b) emission spectra of solvatofluorochromism of $\mathbf{1 d}$.

(a)

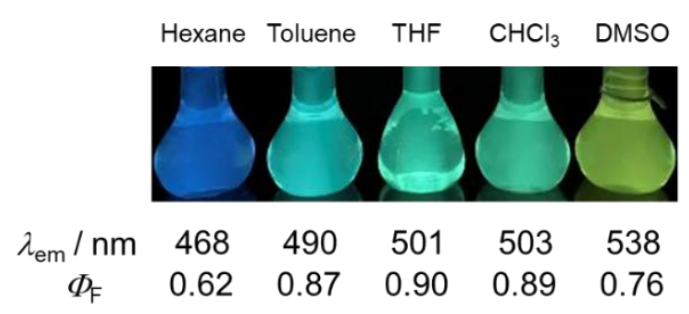

(b)

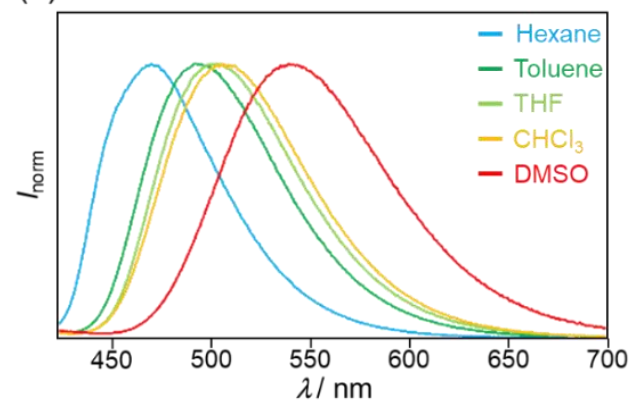

Figure S5 (a) Photographs and (b) emission spectra of solvatofluorochromism of 1 e.

(a)

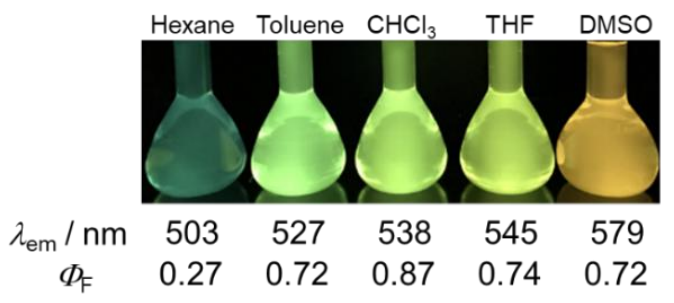

(b)

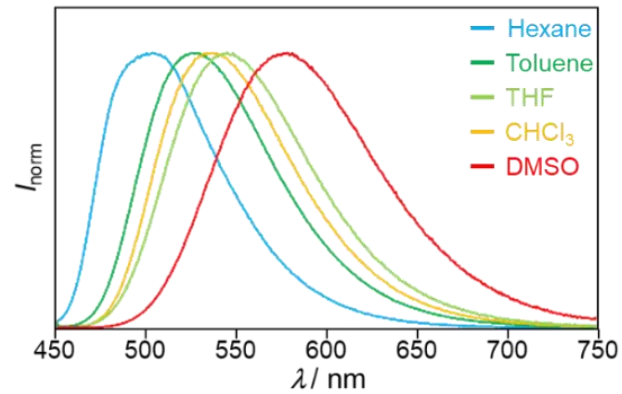

Figure S6 (a) Photographs and (b) emission spectra of solvatofluorochromism of $\mathbf{1 f}$. 
(a)

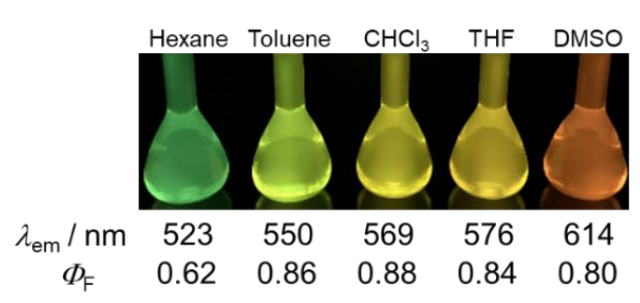

(b)

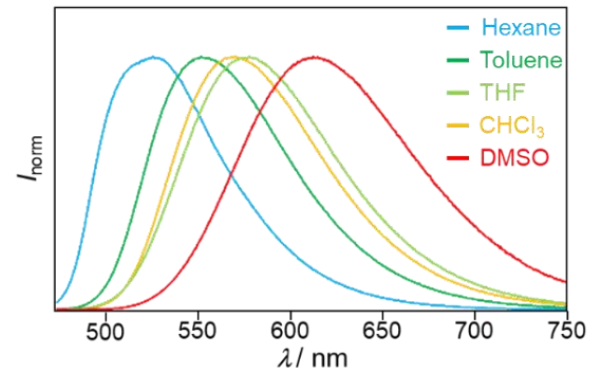

Figure S7 (a) Photographs and (b) emission spectra of solvatofluorochromism of 1g.

\section{Theoretical Calculations}

The theoretical calculations of $\mathbf{1 a}-\mathbf{g}$ were performed using the Gaussian 16 program. ${ }^{3}$ An optimization of the molecular structures of $\mathbf{1 a}$ and $\mathbf{1 d}$ was carried out by density functional theory (DFT) calculations at the CAM-B3LYP/6-31G(d) level of theory (Figure S8). The six lowest singletsinglet transitions of $\mathbf{1 a}$ and $\mathbf{1 d}$ were calculated using time-dependent density functional theory (TD-DFT) calculations at the CAM-B3LYP/6-31G(d) level of theory. Here, the long-range-corrected hybrid functional CAM-B3LYP was used, as CAM-B3LYP often provides better results in TD-DFT calculations than B3LYP, which is conventionally used in DFT calculations. ${ }^{4}$ The TD-DFT calculations of $\mathbf{1 b}-\mathbf{g}$ using the structures obtained from the single-crystal X-ray diffraction analysis were also carried out at the CAM-B3LYP/6-31G(d) level of theory (Figure S9).

(a)

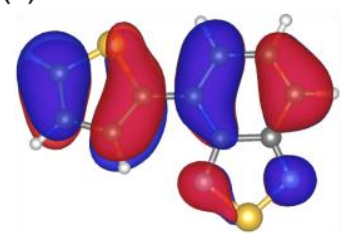

HOMO: $-7.10 \mathrm{eV}$

calcd. absorption $\lambda_{\text {abs }}=355.35 \mathrm{~nm}$, oscillator strength $f=0.2288$, transition from HOMO to LUMO = 0.69697 (b)

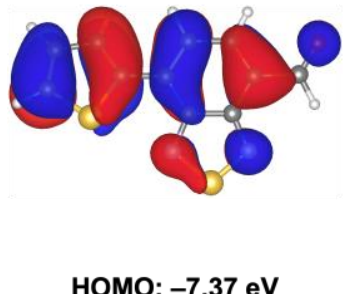

calcd. absorption $\lambda_{\text {abs }}=375.08 \mathrm{~nm}$, oscillator strength $f=0.3788$, transition from HOMO to LUMO $=0.69869$

Figure S8 HOMO and LUMO of the optimized structures of (a) 1a and (b) 1d calculated at the CAM-B3LYP/6-31G(d) level. The structures are drawn by VESTA. ${ }^{5}$ 
(a)

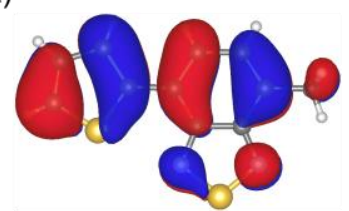

HOMO: $-6.70 \mathrm{eV}$

calcd. absorption $\lambda_{\text {abs }}=378.90 \mathrm{~nm}$, oscillator strength $f=0.2464$ transition from HOMO to LUMO $=0.69875$

(c)

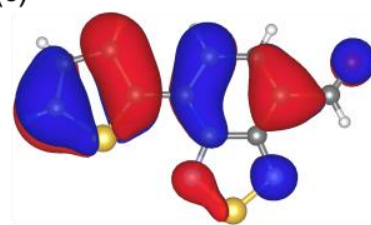

HOMO: $-7.06 \mathrm{eV}$

calcd. absorption $\lambda=398.71 \mathrm{~nm}$, oscillator strength $f=0.3782$, transition from HOMO to LUMO $=0.70003$

(e)

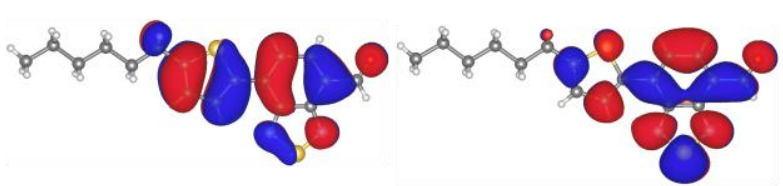

HOMO: $-7.12 \mathrm{eV}$

LUMO: $-1.75 \mathrm{eV}$

calcd. absorption $\lambda_{\text {abs }}=387.06 \mathrm{~nm}$, oscillator strength $f=0.4524$, transition from HOMO to LUMO $=0.69852$

(b)

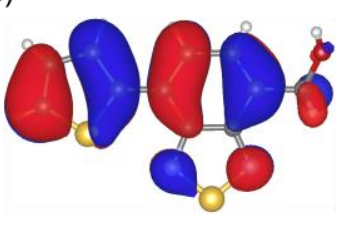

HOMO: $-6.89 \mathrm{eV}$

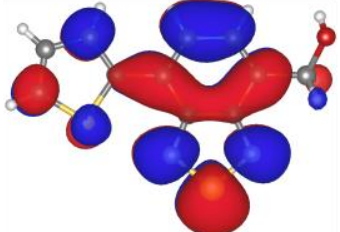

LUMO: $-1.32 \mathrm{eV}$

calcd. absorption $\lambda_{\text {abs }}=374.08 \mathrm{~nm}$, oscillator strength $f=0.2448$, transition from HOMO to LUMO $=0.69883$

(d)

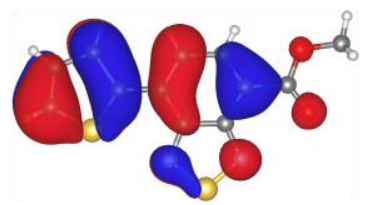

HOMO: $-6.87 \mathrm{eV}$

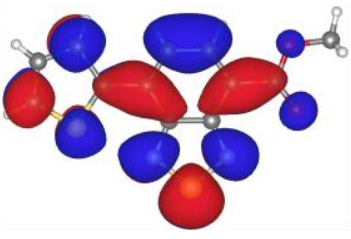

LUMO: $-1.56 \mathrm{eV}$

calcd. absorption $\lambda=392.85 \mathrm{~nm}$, oscillator strength $f=0.4066$ transition from HOMO to LUMO $=0.70080$

(f)

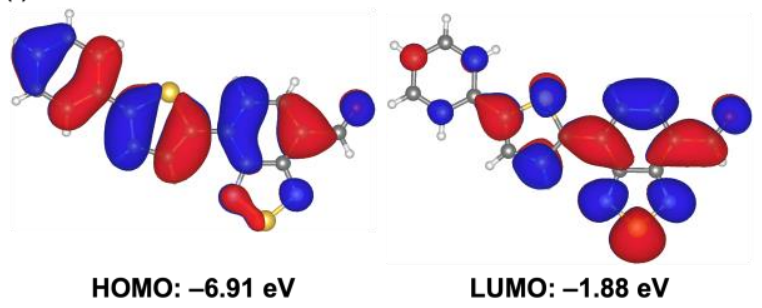

calcd. absorption $\lambda_{\text {abs }}=409.73 \mathrm{~nm}$, oscillator strength $f=0.6634$, transition from HOMO to LUMO $=0.68805$

Figure S9 HOMO and LUMO of the X-ray structures of (a) 1b, (b) 1c, (c) 1d, (d) 1e, (e) 1f, and (f)

$1 \mathrm{~g}$ calculated at the CAM-B3LYP/6-31G(d) level. The structures are drawn by VESTA. ${ }^{5}$ 


\section{Single-crystal X-ray structures}

\section{ORTEP structures of $1 \mathbf{a}-\mathbf{g}$}

The ORTEP structures for the single crystals of 1a-g are shown in Figure S10. For 1a, 1c, and 1d, thienyl groups were disordered over two orientations. The thienyl group of $\mathbf{1 a}$ and $\mathbf{1 c}$ were refined with isotropic displacement parameters due to the disordered orientations.

(a)

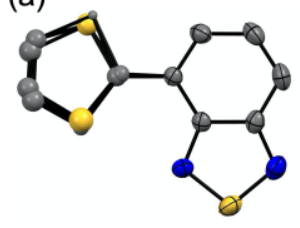

(b)

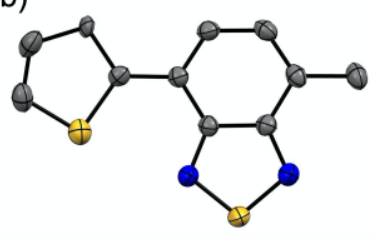

(c)

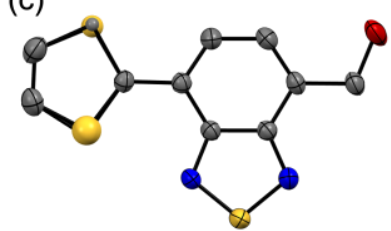

(d)

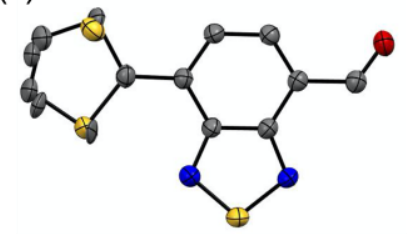

(e)

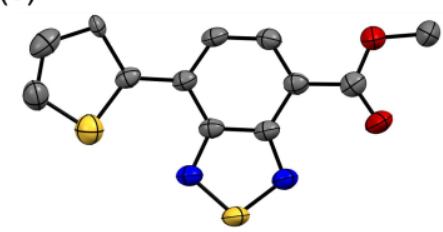

(g)

(f)

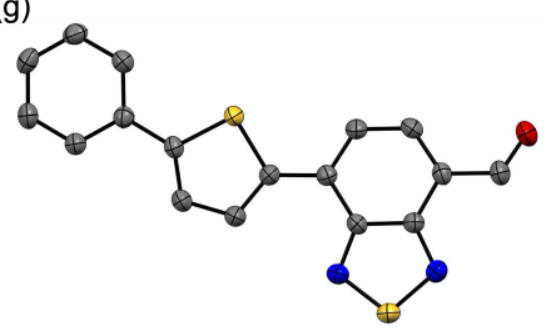

Figure S10 Single-crystal X-ray structures of $1 \mathbf{a}-\mathbf{g}$ with atomic displacement parameters set at 50\% probability (Color code: gray $=\mathrm{C}$, blue $=\mathrm{N}$, red $=\mathrm{O}$, yellow $=\mathrm{S}$ ). All hydrogen atoms are omitted for clarity. (a) 1a (CCDC2111903), (b) 1b (CCDC2111904), (c) 1c (CCDC2111905), (d) 1d (CCDC2111906), (e) 1e (CCDC2111907), (f) 1f (CCDC2111908), and (g) 1g (CCDC2111909) 
(a)

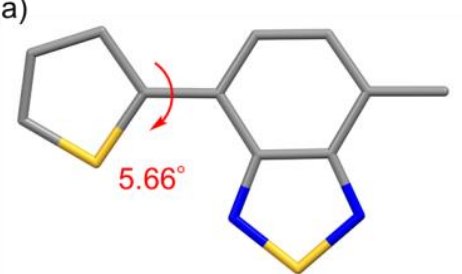

(b)

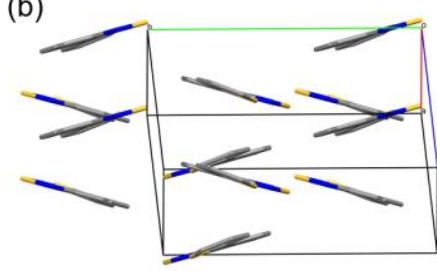

(c)

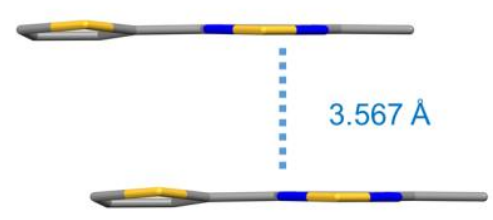

(d)

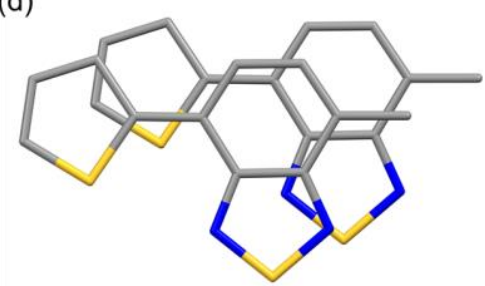

Figure S11 (a) The molecular structure, (b) packing structure, (c and d) side and top view of two adjacent molecules of $\mathbf{1 b}$.

(a)

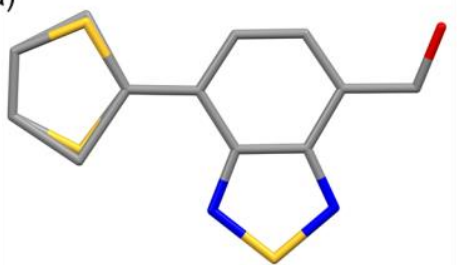

(b)

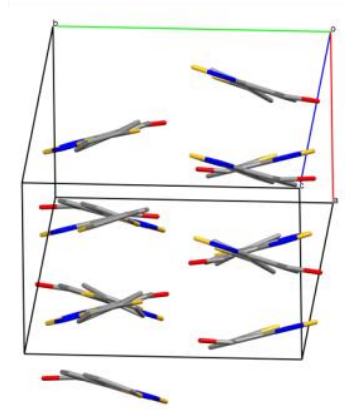

(c)

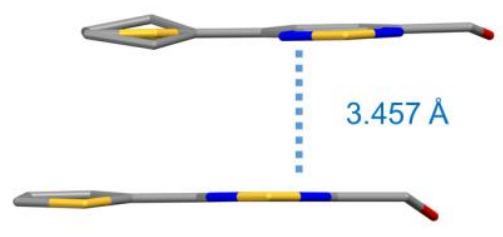

(d)

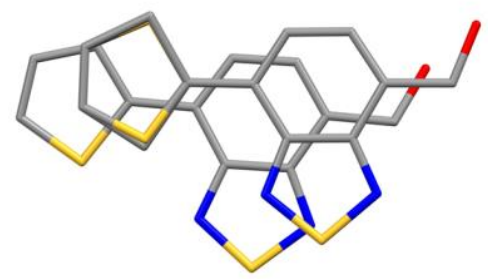

Figure S12 (a) The molecular structure, (b) packing structure, (c and d) side and top view of two adjacent molecules of $\mathbf{1 c}$. 
(a)

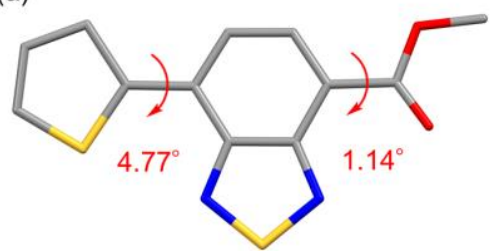

(b)

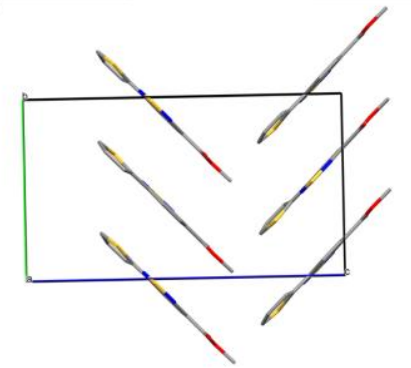

(c)

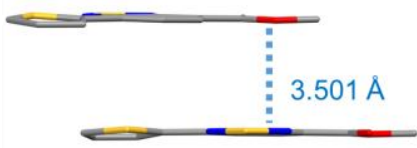

(d)

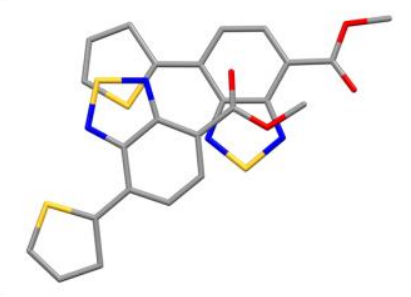

(e)

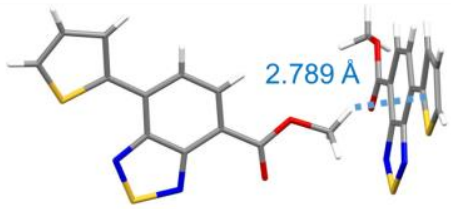

(f)

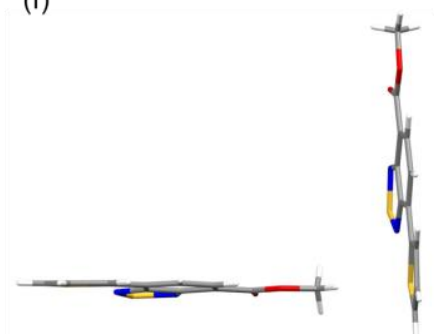

Figure S13 (a) The molecular structure, (b) packing structure, (c-f) side and top view of two adjacent molecules of $1 \mathrm{e}$. 


\section{Supplementary spectra for the mechanochromic luminescence}

Absorption spectra of crystalline and ground 1a-g and heated 1d-g are shown in Figure S14.

(a)

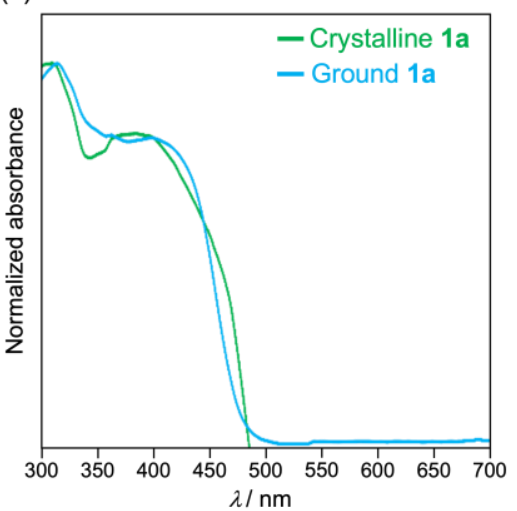

(d)

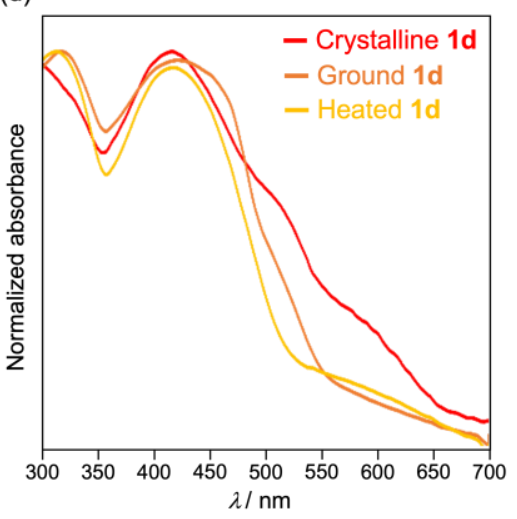

(b)

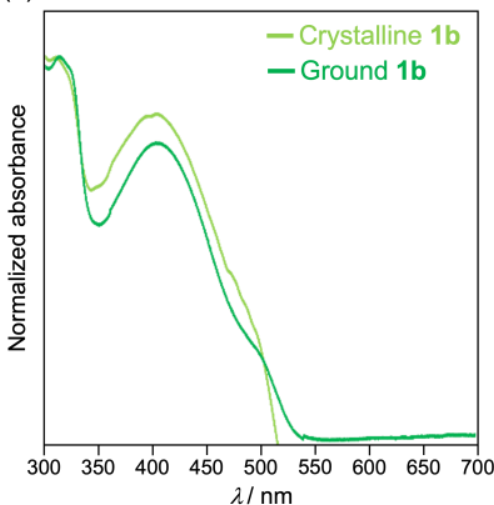

(e)

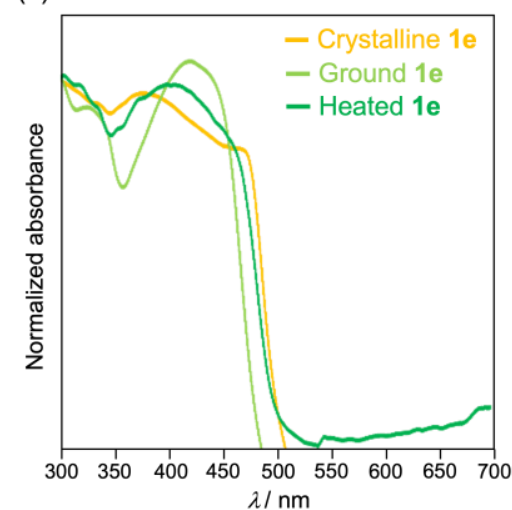

(g)

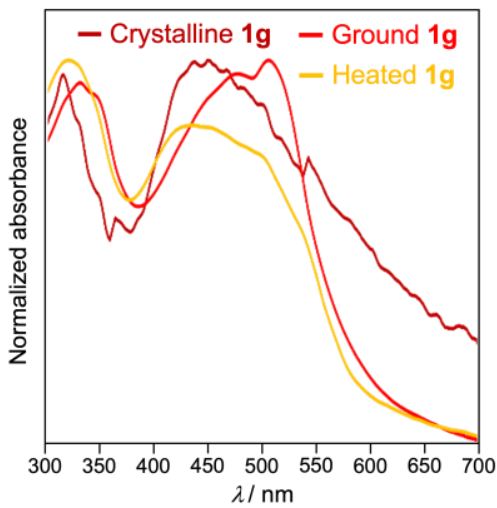

(c)

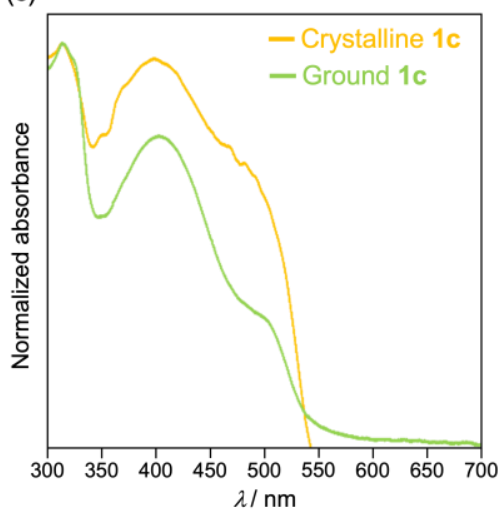

(7)

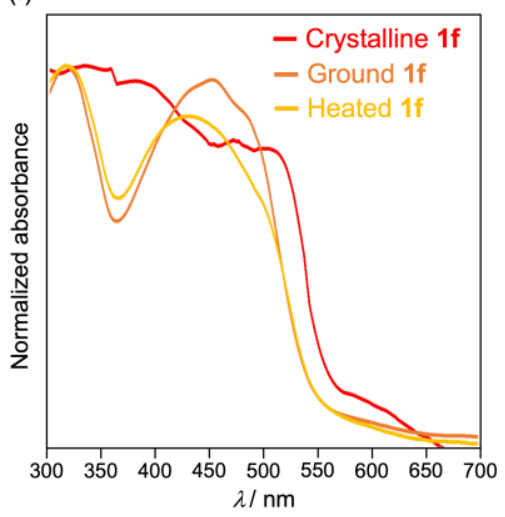


Fluorescence spectra showed hypsochromic shifts in maximum emission wavelengths for the bicolor emission switching of $\mathbf{1 b}$ and $\mathbf{1 c}$ and tricolor emission switching of $\mathbf{1 d - f}$ (Figure S15).

(a)

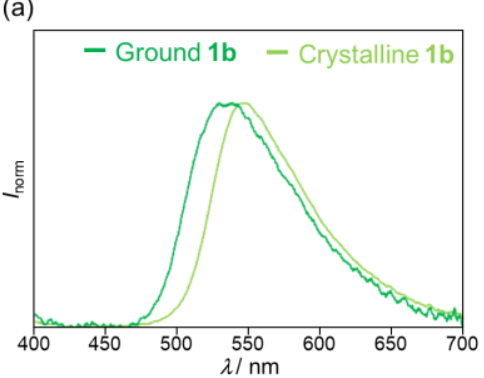

(c)

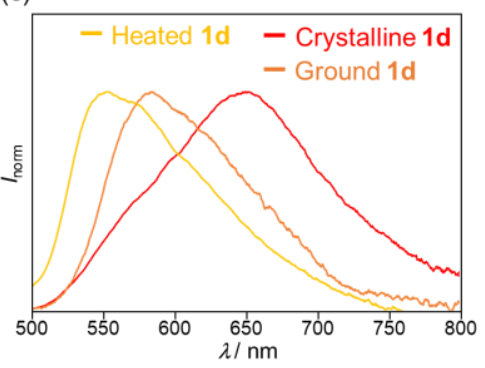

(b)

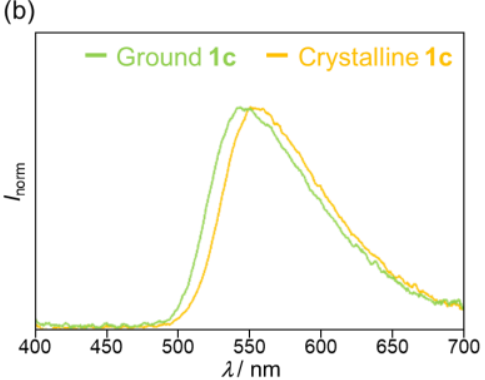

(e)

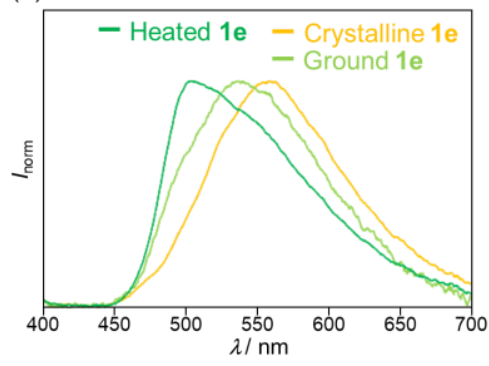

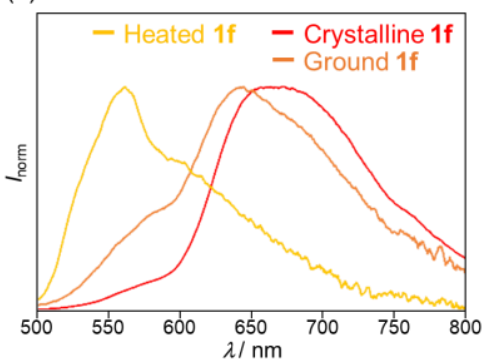

Figure S15 Fluorescence spectra for ( $a$ and b) bicolor emission switching of $\mathbf{1 b}$ and $\mathbf{1 c}$ and (c-e) tricolor emission switching of $\mathbf{1 d}-\mathbf{f}\left(\lambda_{\mathrm{ex}}=365 \mathrm{~nm}\right)$.

The FTIR spectrum of heated 1d was in good agreement with that of crystalline 1d. Slight shifts in the $\mathrm{C}=\mathrm{O}$ and $\mathrm{C}=\mathrm{C}$ stretching bands were observed for ground $\mathbf{1 d}$ compared to those of crystalline and heated samples (Figure S16).

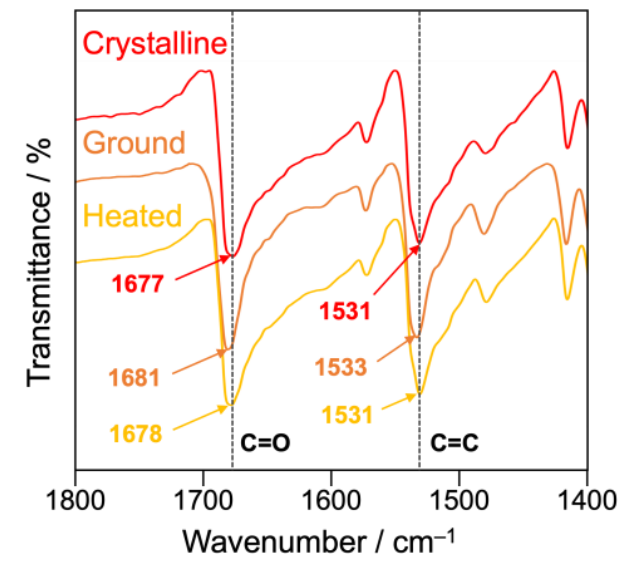

Figure S16 Partial FTIR spectra for the tricolor emission switching of 1 d. 


\section{PXRD analyses}

PXRD patterns showed that the intensity of diffraction peaks in crystalline samples decreased after grinding. The intensity was recovered on heating, and the ratio of the peak intensities was different from that of the initial crystalline samples (Figure S17-23).

(a)

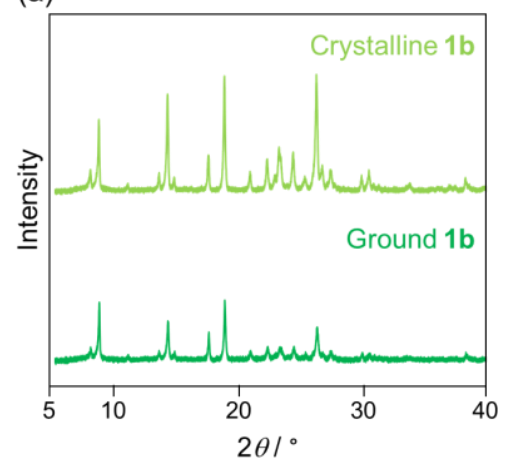

(b)

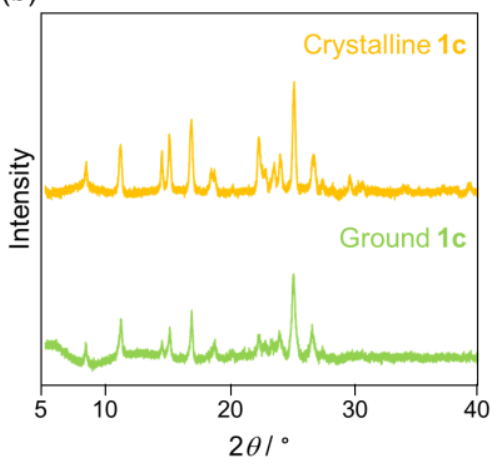

(c)

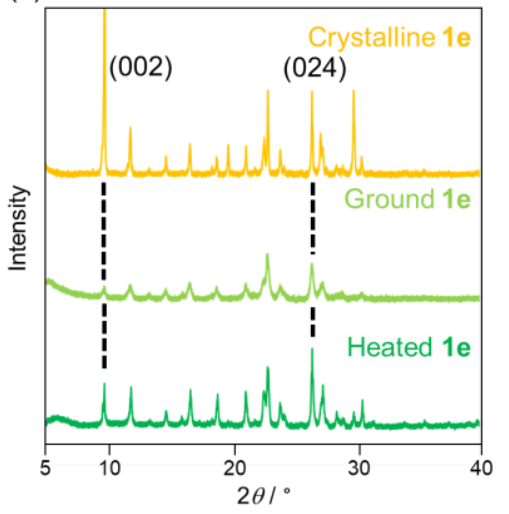

(d)

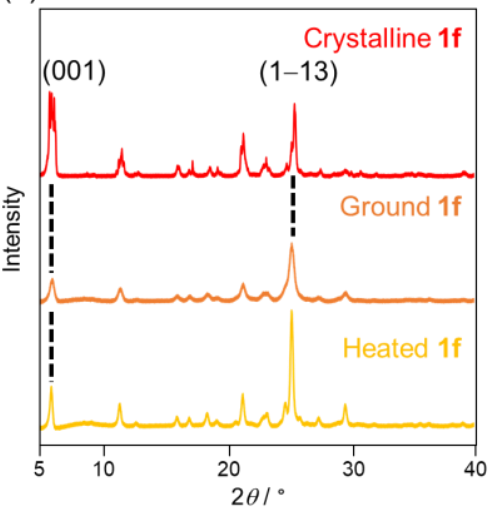

(e)

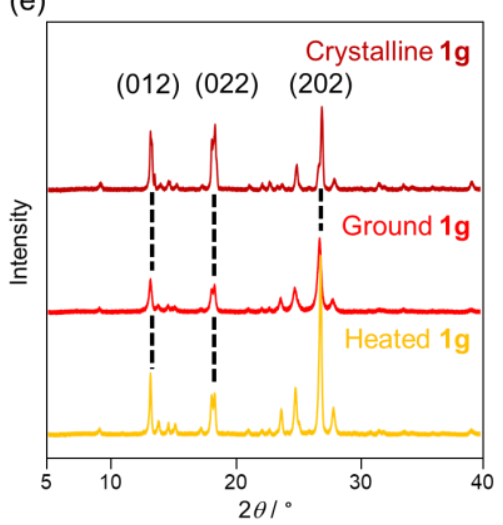

Figure S17 PXRD patterns for (a and b) bicolor emission switching of $\mathbf{1 b}$ and $\mathbf{1 c}$ and (c-e) tricolor emission switching of $\mathbf{1 e -} \mathbf{- g}$. 


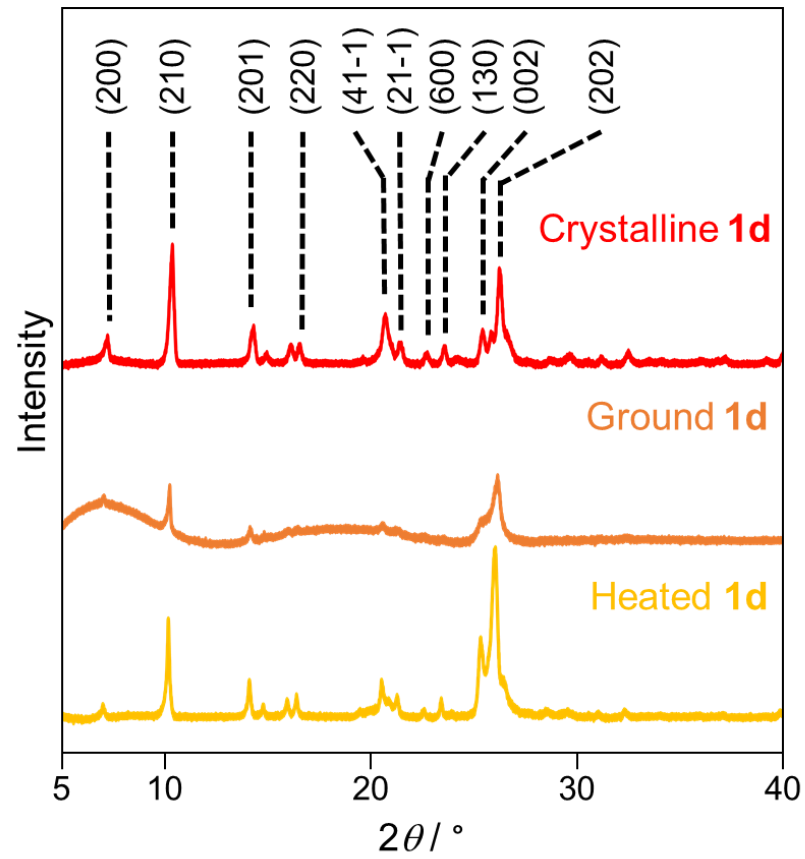

Figure S18 PXRD patterns for tricolor emission switching of $\mathbf{1 d}$. 
Along $b$-axis
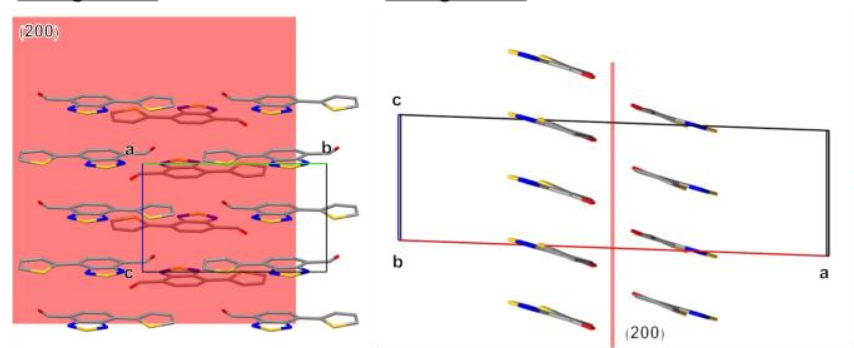

Along c-axis

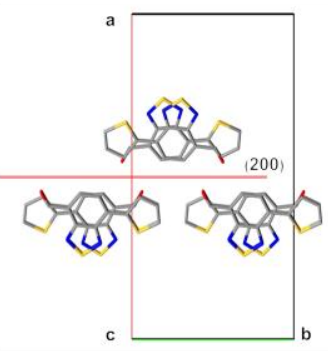

(b) (201) crystal plane

Along a-axis

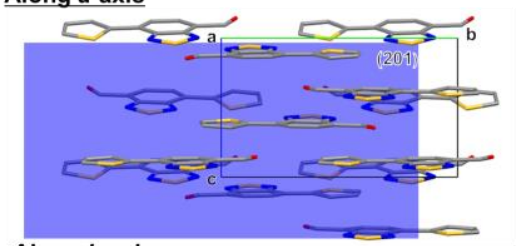

Along $b$-axis

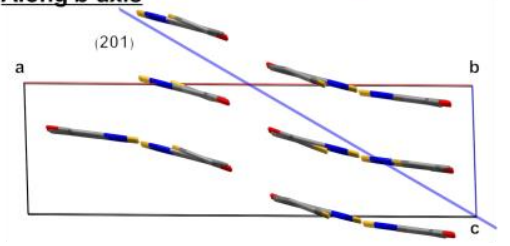

(c) (220) crystal plane

$$
\text { Along a-axis }
$$

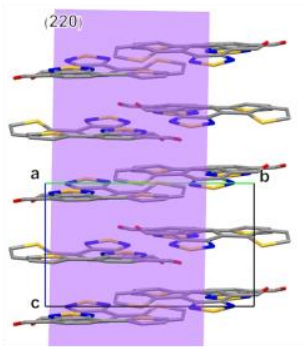

(d) (41-1) crystal plane

Along a-axis

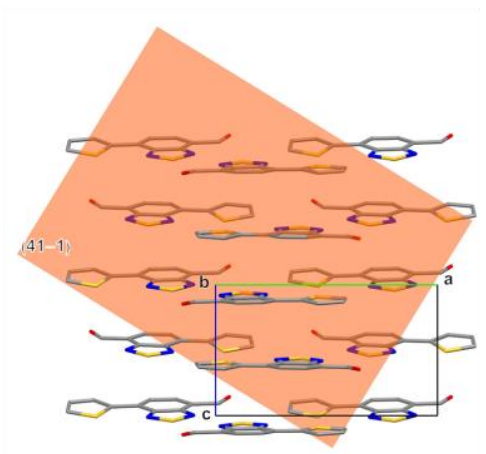

Along $b$-axis

\section{Along $c$-axis}
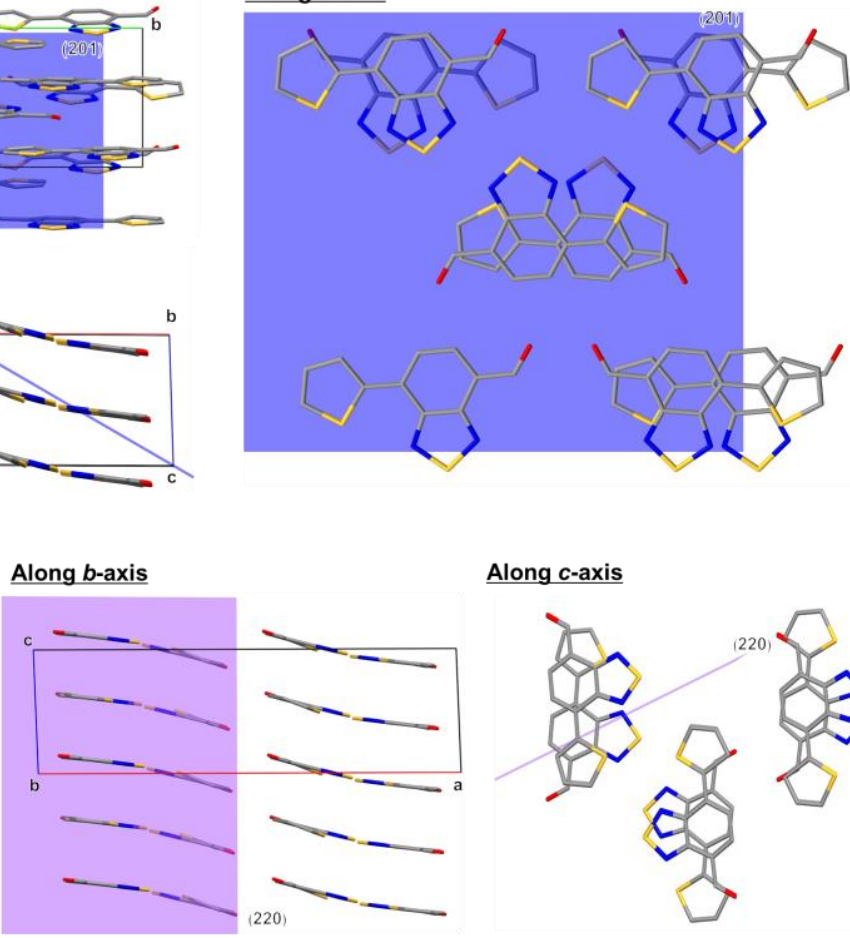

Along c-axis

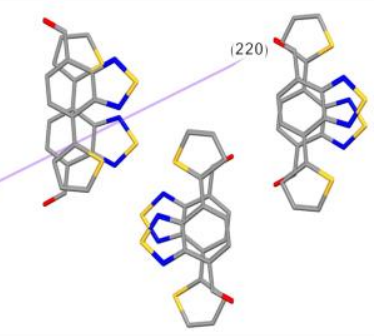

Along $c$-axis

Along $b$-axis

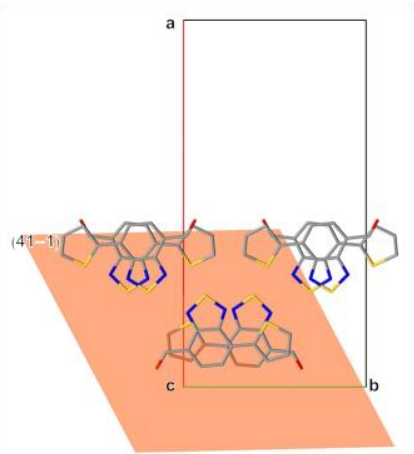

Figure S19 Intermolecular interaction of 1d on (a) (200) crystal plane, (b) (201) crystal plane, (c) (220) crystal plane, and (d) (41-1) crystal plane. 
(a) (21-1) crystal plane

Along a-axis

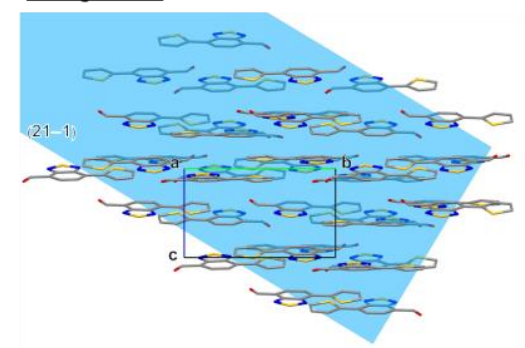

Along $b$-axis

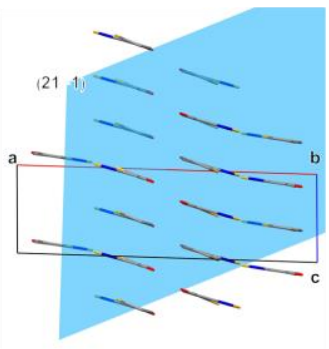

Along c-axis

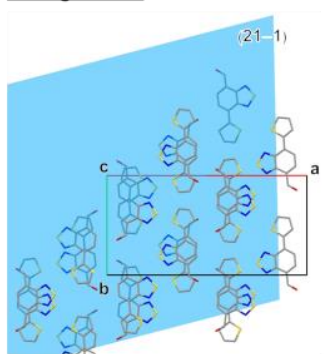

(b) (600) crystal plane

Along a-axis

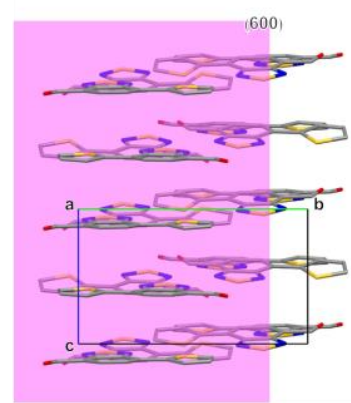

Along $b$-axis

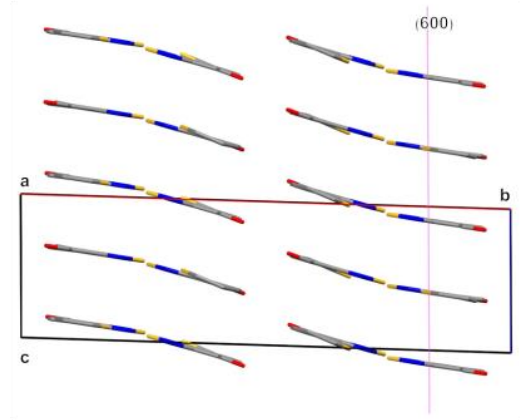

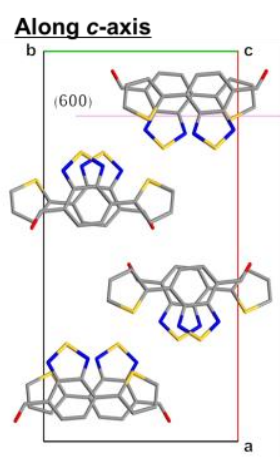

(c) (130) crystal plane

\section{Along a-axis}

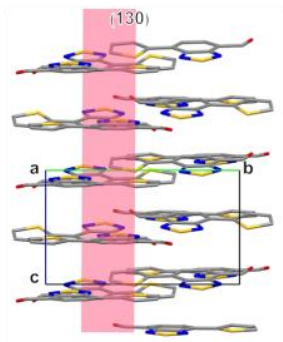

Along $b$-axis

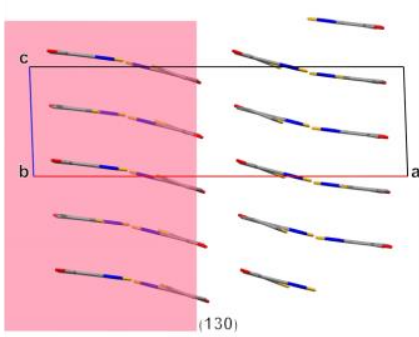

Along $c$-axis

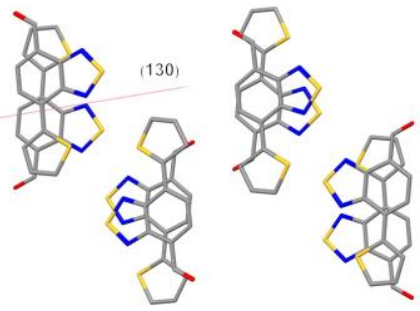

(d) (002) crystal plane

Along a-axis

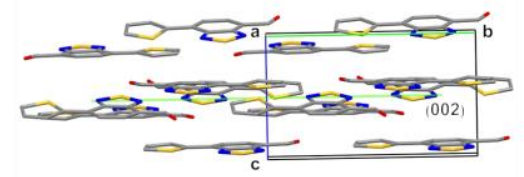

Along $b$-axis

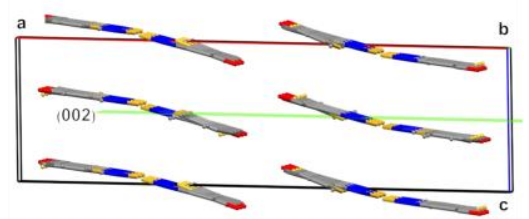

Along c-axis

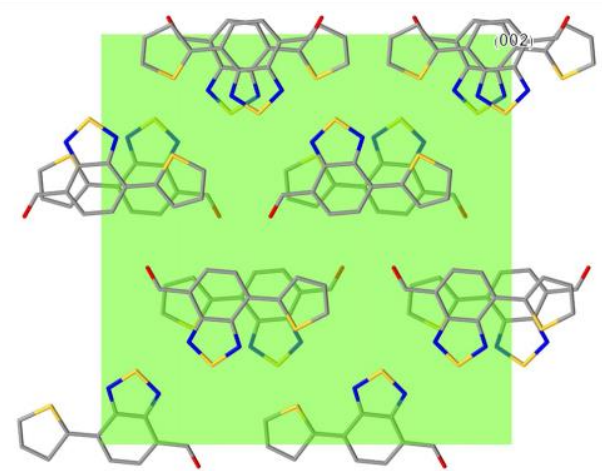

Figure S20 Intermolecular interaction of 1d on (a) (21-1) crystal plane, (b) (600) crystal plane, (c) (130) crystal plane, and (d) (002) crystal plane. 
(a) (002) crystal plane

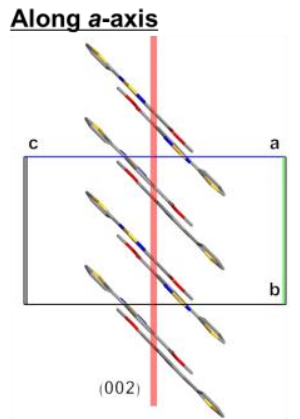

(b) (024) crystal plane

Along a-axis

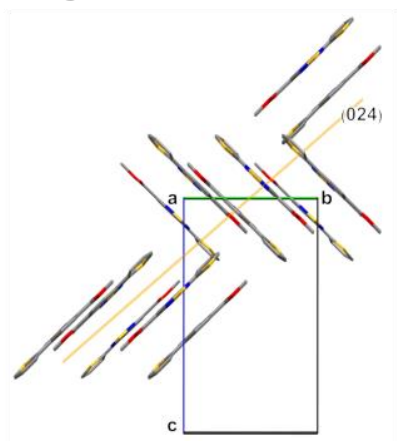

Along $b$-axis

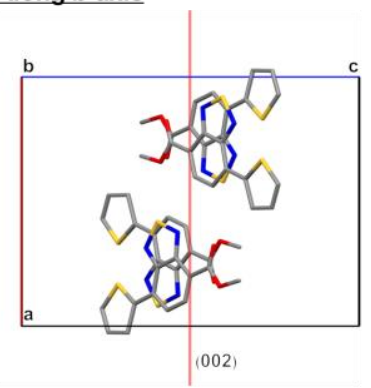

Along $c$-axis
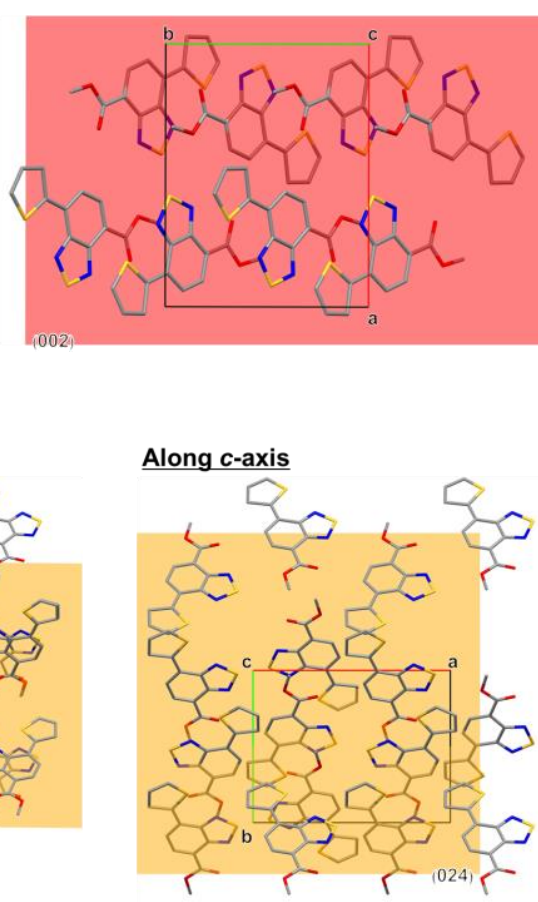

Along $c$-axis

Figure S21 Intermolecular interaction of 1e on (a) (002) crystal plane and (b) (024) crystal plane.

(a) (001) crystal plane
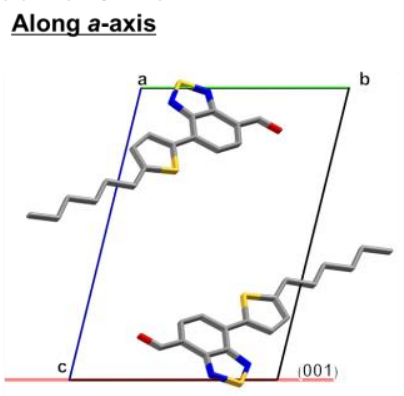

(b) (1-13) crystal plane

Along a-axis

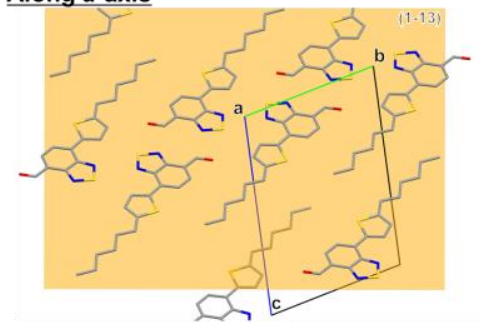

Along $b$-axis

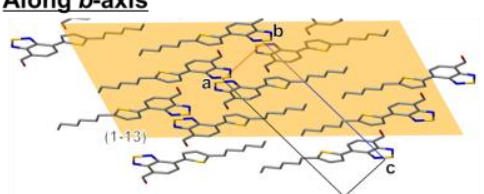

Along $b$-axis

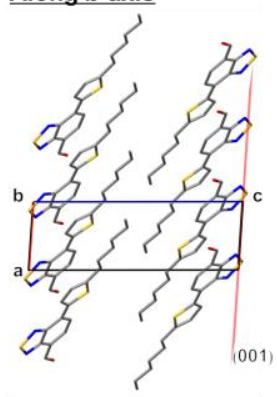

Along c-axis

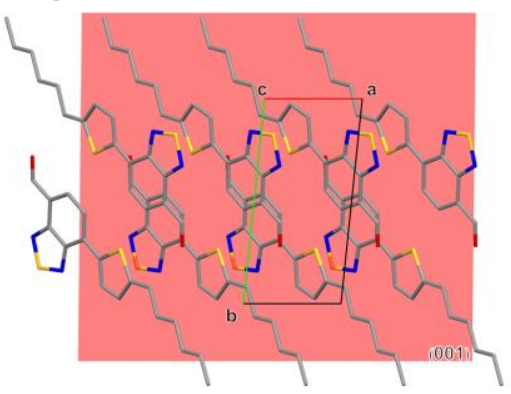

Along $b$-axis

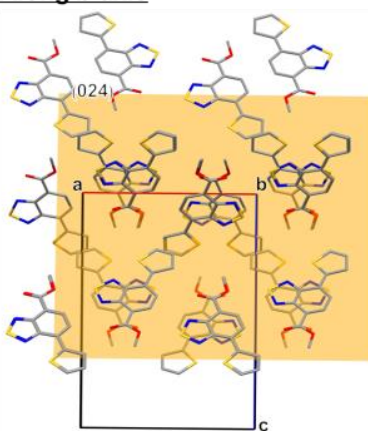


(a) (012) crystal plane

Along a-axis

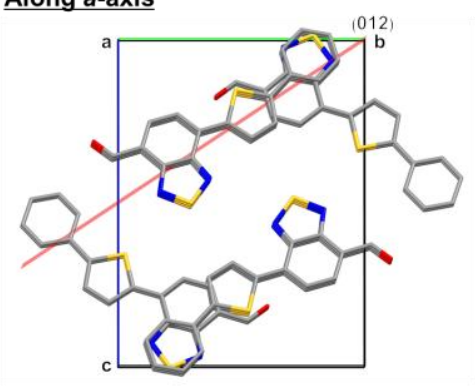

(b) (022) crystal plane

Along a-axis

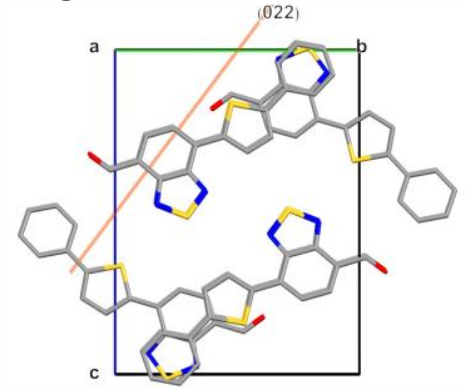

(c) (202) crystal plane

Along a-axis

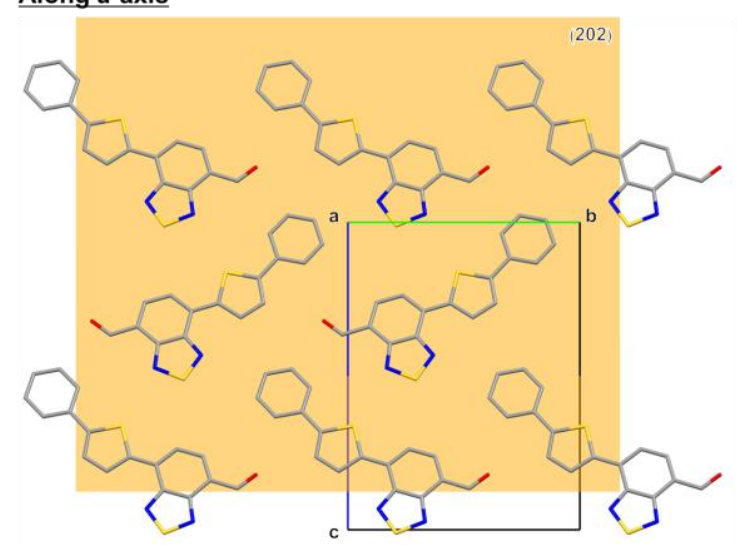

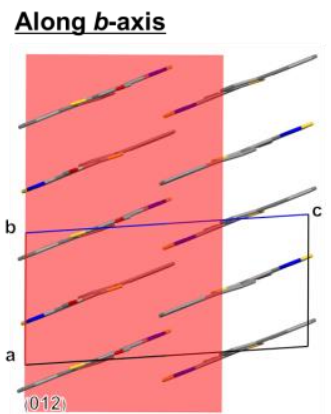

Along c-axis

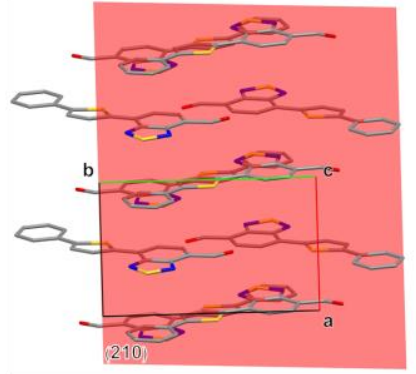

Along c-axis
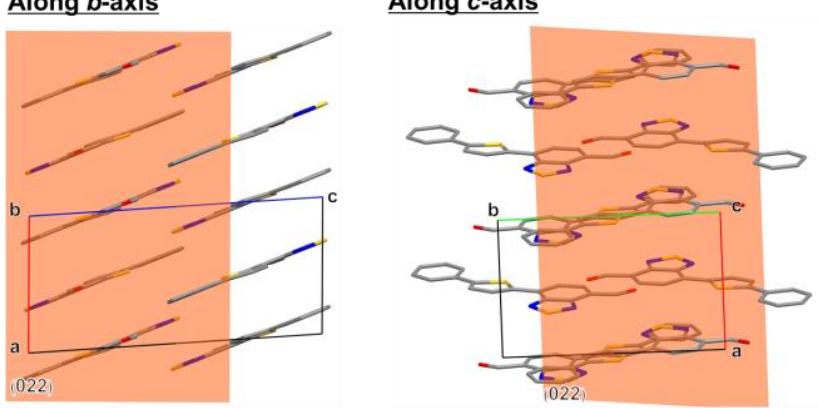

Along c-axis

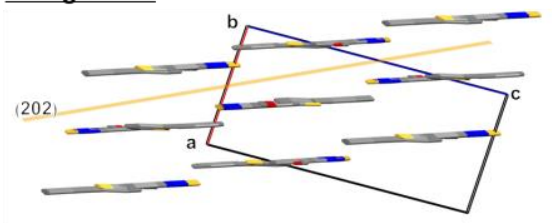

Along $b$-axis

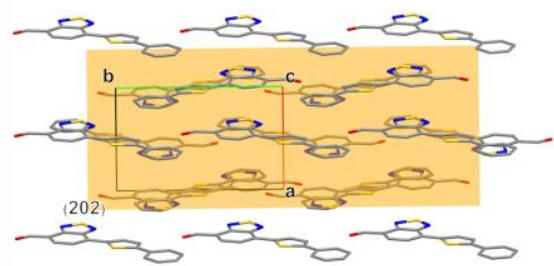

Figure S23 Intermolecular interaction of $\mathbf{1 g}$ on (a) (012) crystal plane, (b) (022) crystal plane and (c) (202) crystal plane. 


\section{DSC thermograms}

In the DSC diagrams, the only one endothermic peak corresponding to the melting point was observed for the crystalline, ground, and heated samples (Figure S24)

(a)

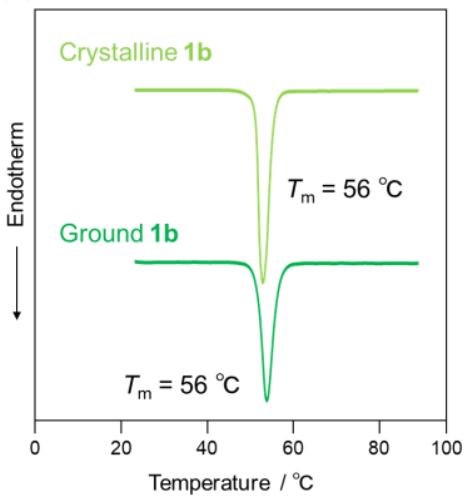

(b)

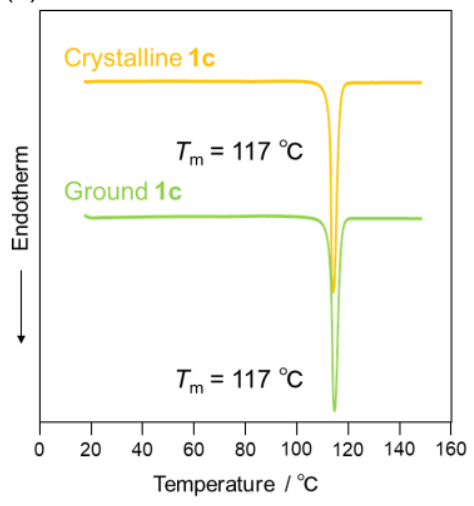

(c)

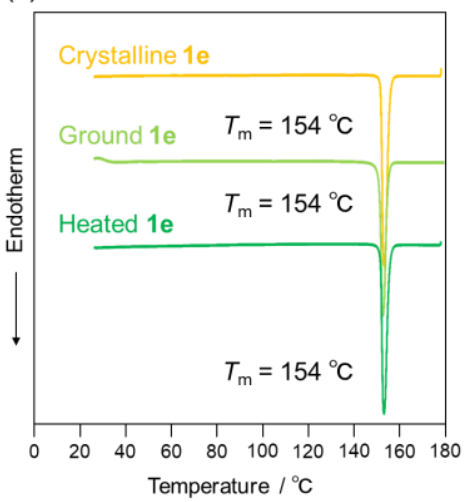

(d)

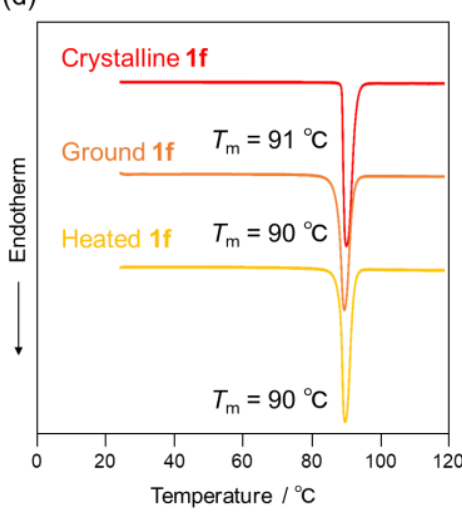

(e)

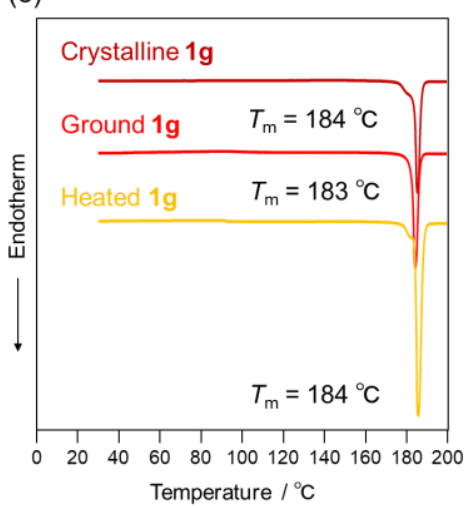

Figure S24 DSC thermograms for (a and b) the crystalline and ground samples of $\mathbf{1 b}$ and $\mathbf{1 c}$ and (c-e) the crystalline, ground, and heated samples of $\mathbf{1 e -} \mathbf{g}$. 


\section{Measurements of fluorescence lifetimes}

(a)
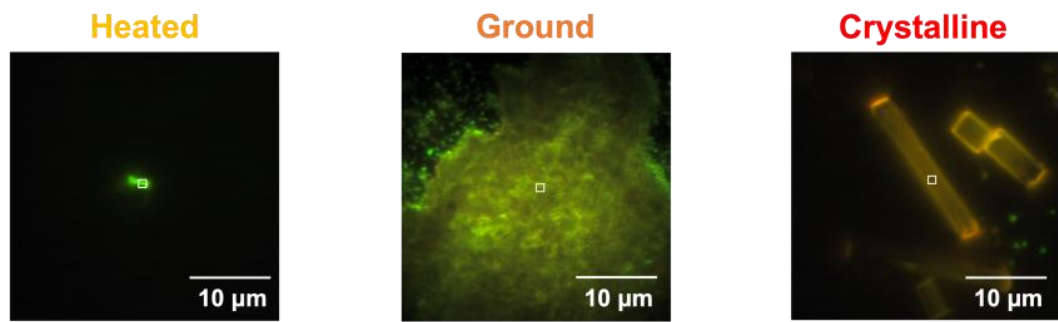

(b)

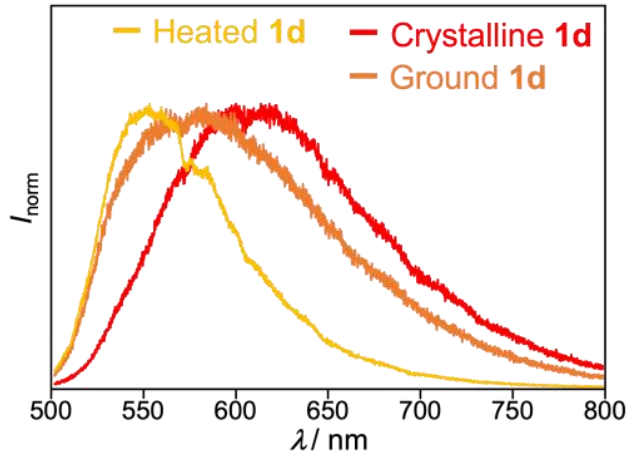

(c)

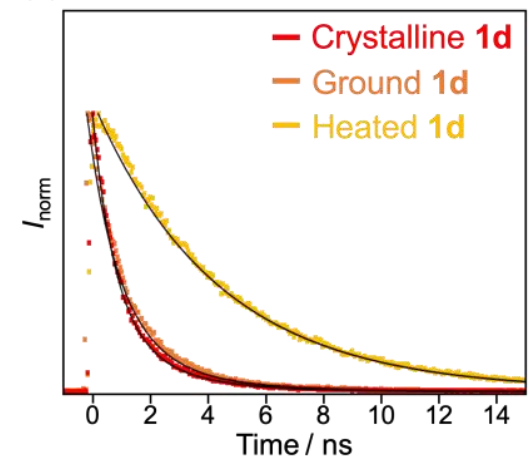

Figure S25 Photographs, fluorescence spectra, and fluorescence decay profiles recorded by spatially resolved fluorescence microscopy $\left(\lambda_{\mathrm{ex}}=405 \mathrm{~nm}\right.$ ). (a) Photographs of crystalline 1d, ground 1d, and heated 1d. The square marks indicate the measured locations of fluorescence spectra and fluorescence decay profiles. (b) Fluorescence spectra of crystalline 1d (red), ground 1d (orange), and heated 1d (yellow). (c) Fluorescence decay profiles of crystalline 1d (red), ground 1d (orange), and heated 1d (yellow) monitored $>425 \mathrm{~nm}$. The black lines indicate double- (crystalline and ground) and single-exponential (heated) curves fitted to the time profiles. 
(a)
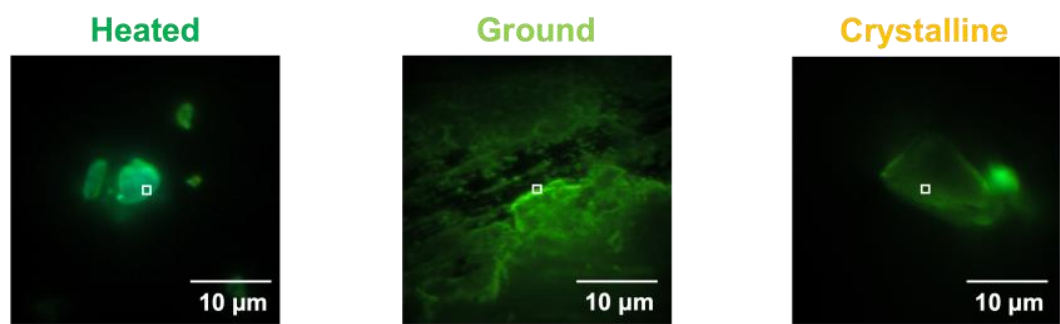

(b)

(c)
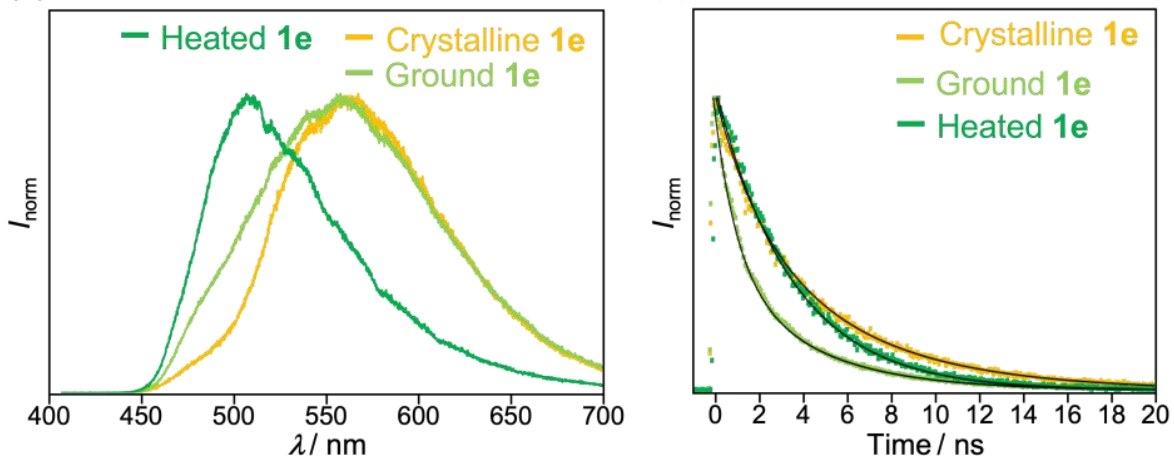

Figure S26 Photographs, fluorescence spectra, and fluorescence decay profiles recorded by spatially resolved fluorescence microscopy $\left(\lambda_{\mathrm{ex}}=405 \mathrm{~nm}\right.$ ). (a) Photographs of crystalline 1e, ground 1e, and heated 1e. The square marks indicate the measured locations of fluorescence spectra and fluorescence decay profiles. (b) Fluorescence spectra of crystalline (yellow), ground 1e (yellow-green), and heated 1e (green). (c) Fluorescence decay profiles of crystalline 1e (yellow), ground 1e (yellow-green), and heated 1e (green) monitored $>425 \mathrm{~nm}$. The black lines indicate double- (crystalline and ground) and single-exponential (heated) curves fitted to the time profiles. 


\section{References}

1) Liu, H.; Yan, S.; Huang, R.; Gao, Z.; Wang, G.; Ding, L.; Fang, Y. Single-Benzene-Based Solvatochromic Chromophores: Color-Tunable and Bright Fluorescence in the Solid and Solution States. Chem. Eur. J. 2019, 25, 16732-16739.

2) Vaidya, S.; Johnson, C.; Wang, X.-Y.; Schmehl, R. H. Fluorescence Solvato and Vapochromism of a Dimethylaminostyryl Terpyridine Derivative. J. Photochem. Photobiol. A 2007, 187, 258262.

3) Gaussian 16, Revision A.03, Frisch, M. J.; Trucks, G. W.; Schlegel, H. B.; Scuseria, G. E.; Robb, M. A.; Cheeseman, J. R.; Scalmani, G.; Barone, V.; Petersson, G. A.; Nakatsuji, H.; Li, X.; Caricato, M.; Marenich, A. V.; Bloino, J.; Janesko, B. G.; Gomperts, R.; Mennucci, B.; Hratchian, H. P.; Ortiz, J. V.; Izmaylov, A. F.; Sonnenberg, J. L.; Williams-Young, D.; Ding, F.; Lipparini, F.; Egidi, F.; Goings, J.; Peng, B.; Petrone, A.; Henderson, T.; Ranasinghe, D.; Zakrzewski, V. G.; Gao, J.; Rega, N.; Zheng, G.; Liang, W.; Hada, M.; Ehara, M.; Toyota, K.; Fukuda, R.; Hasegawa, J.; Ishida, M.; Nakajima, T.; Honda, Y.; Kitao, O.; Nakai, H.; Vreven, T.; Throssell, K.; Montgomery, J. A., Jr.; Peralta, J. E.; Ogliaro, F.; Bearpark, M. J.; Heyd, J. J.; Brothers, E. N.; Kudin, K. N.; Staroverov, V. N.; Keith, T. A.; Kobayashi, R.; Normand, J.; Raghavachari, K.; Rendell, A. P.; Burant, J. C.; Iyengar, S. S.; Tomasi, J.; Cossi, M.; Millam, J. M.; Klene, M.; Adamo, C.; Cammi, R.; Ochterski, J. W.; Martin, R. L.; Morokuma, K.; Farkas, O.; Foresman, J. B.; Fox, D. J. Gaussian, Inc., Wallingford CT, 2016.

4) Jacquemin, D.; Perpète, E. A.; Scuseria, G. E.; Ciofini, I.; Adamo, C. TD-DFT Performance for the Visible Absorption Spectra of Organic Dyes: Conventional versus Long-Range Hybrids. $J$. Chem. Theory Comput. 2008, 4, 123-135.

5) Momma, K.; Izumi, F. VESTA3 for Three-Dimentional Visualization of Crystal, Volumetric and Morphology Data. J. Appl. Crystallogr. 2011, 44, 1272-1276. 
${ }^{1} \mathrm{H}$ NMR spectrum of $1 \mathrm{a}\left(500 \mathrm{MHz}, \mathrm{CDCl}_{3}, \mathrm{rt}\right)$

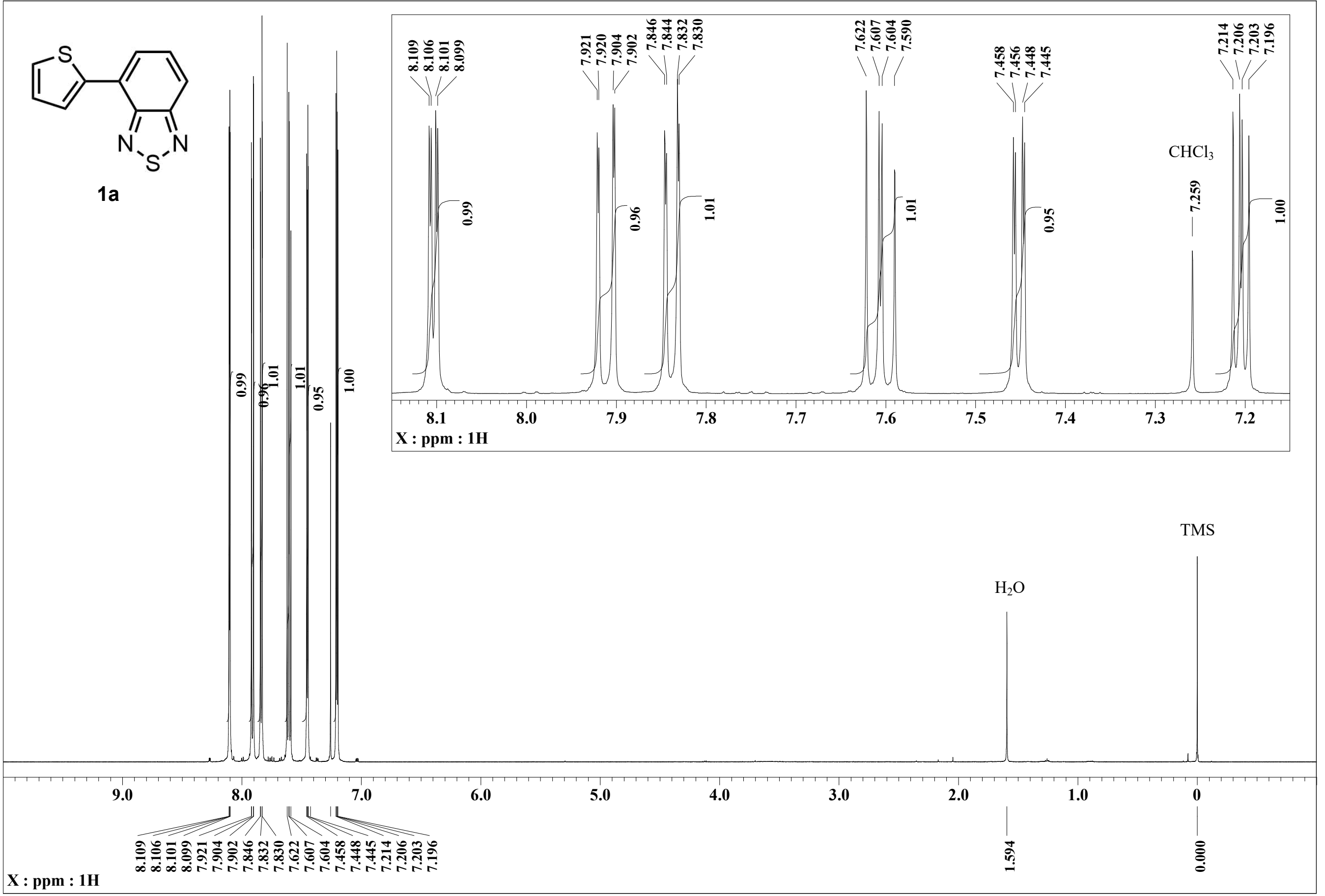


${ }^{13} \mathrm{C}$ NMR spectrum of $1 \mathrm{a}\left(126 \mathrm{MHz}, \mathrm{CDCl}_{3}, \mathrm{rt}\right)$

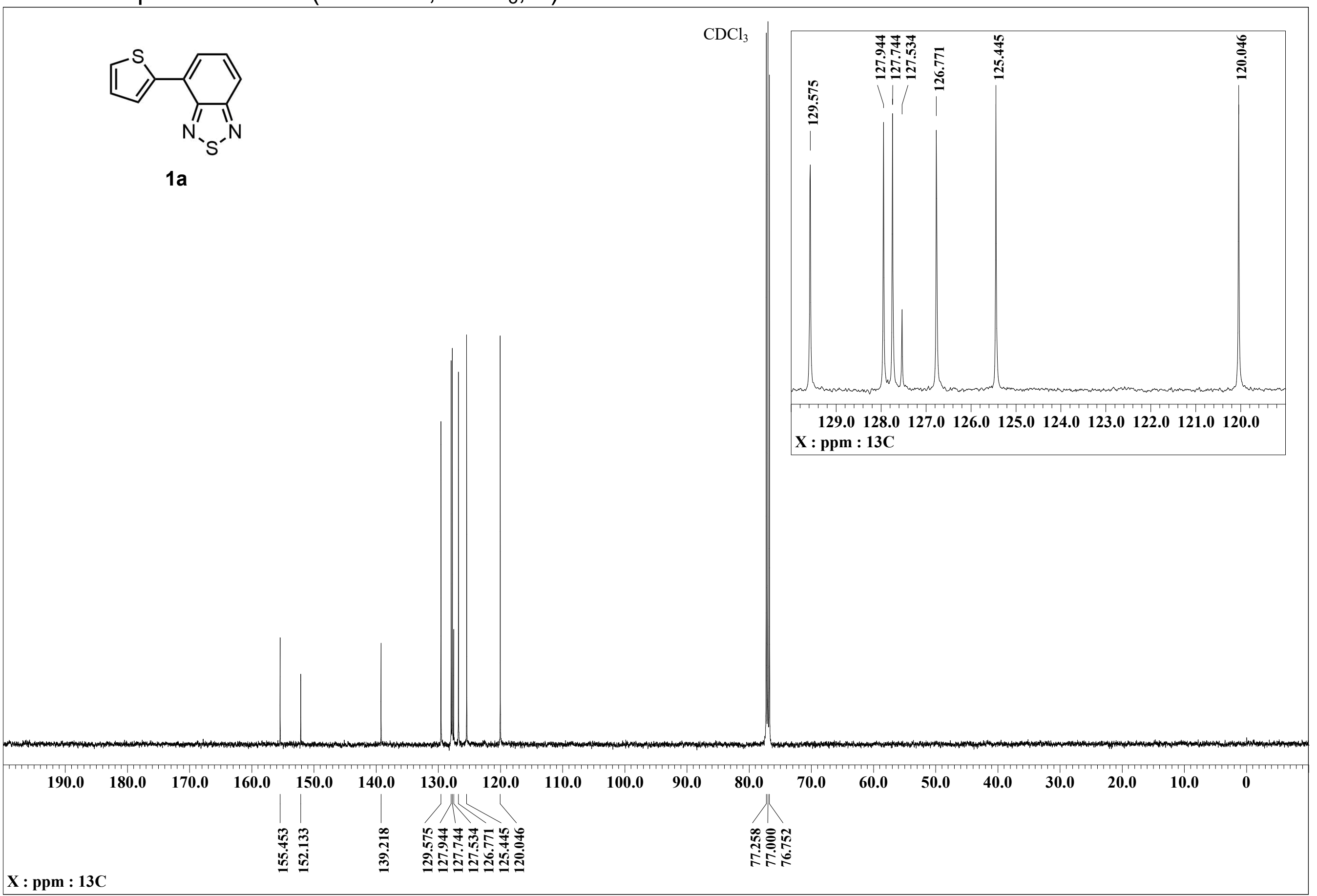


${ }^{1} \mathrm{H}$ NMR spectrum of $\mathbf{1 b}\left(500 \mathrm{MHz}, \mathrm{CDCl}_{3}, \mathrm{rt}\right)$

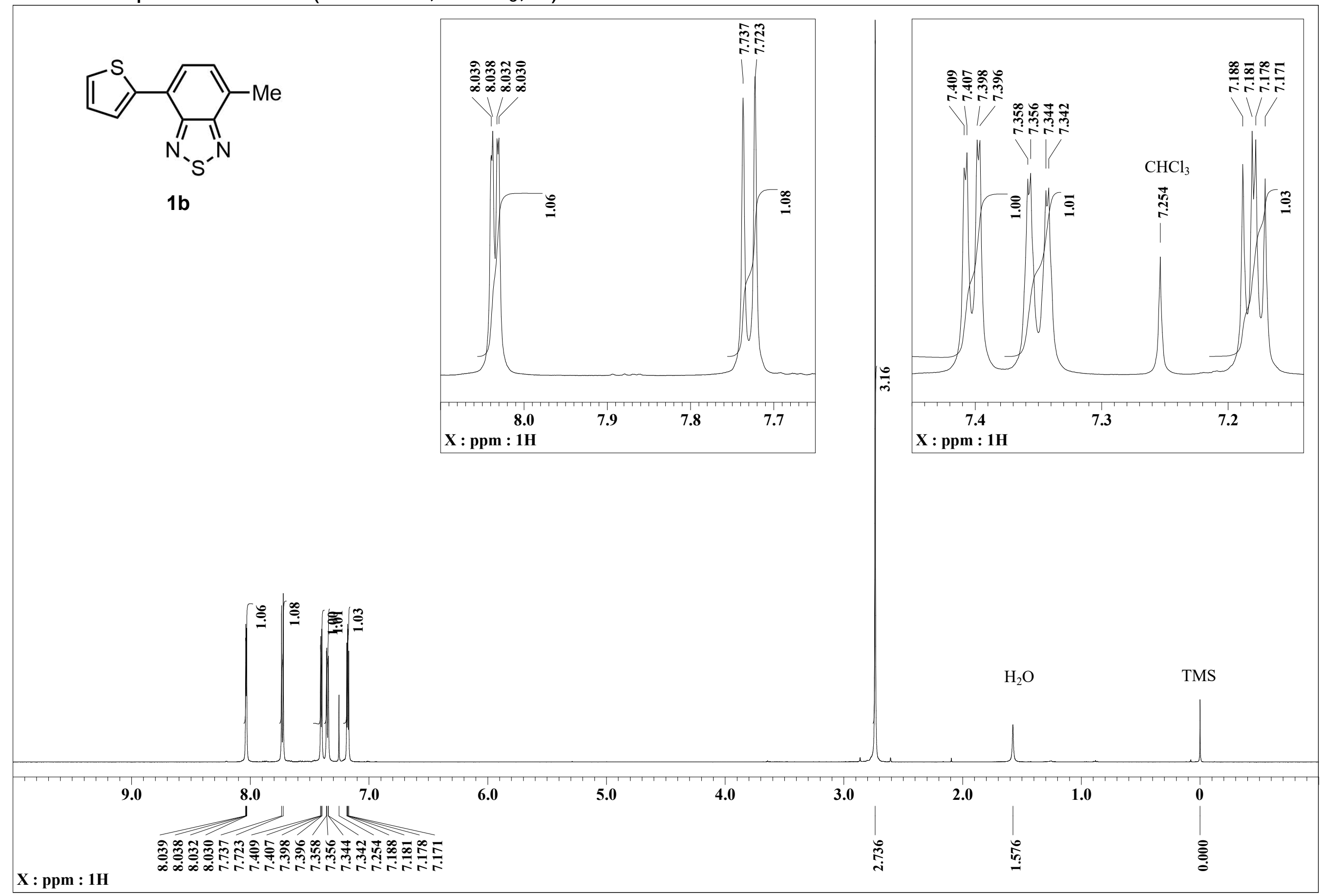


${ }^{13} \mathrm{C}$ NMR spectrum of $\mathbf{1 b}\left(126 \mathrm{MHz}, \mathrm{CDCl}_{3}, \mathrm{rt}\right)$

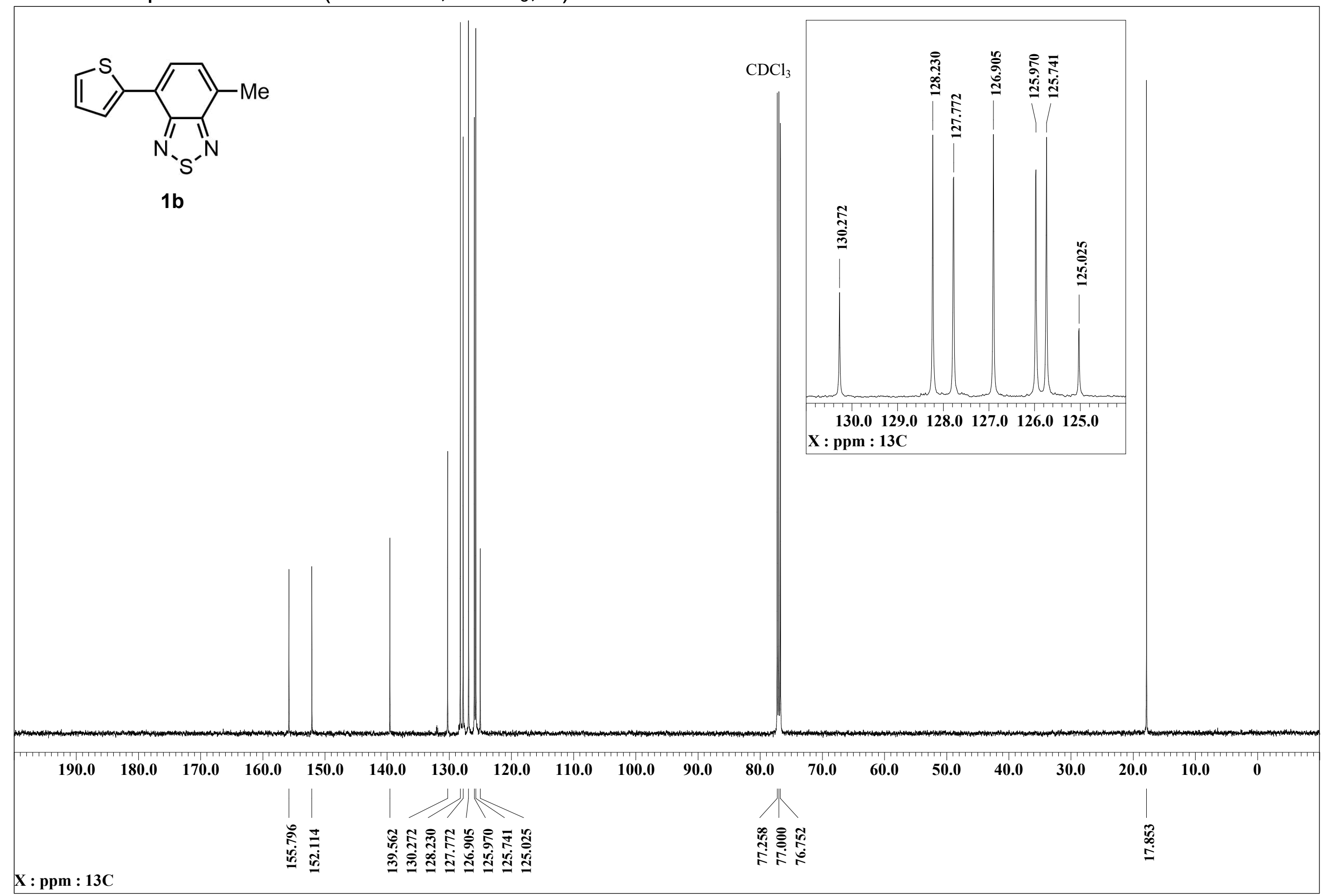


${ }^{1} \mathrm{H}$ NMR spectrum of $1 \mathrm{c}\left(500 \mathrm{MHz}, \mathrm{CDCl}_{3}, \mathrm{rt}\right)$

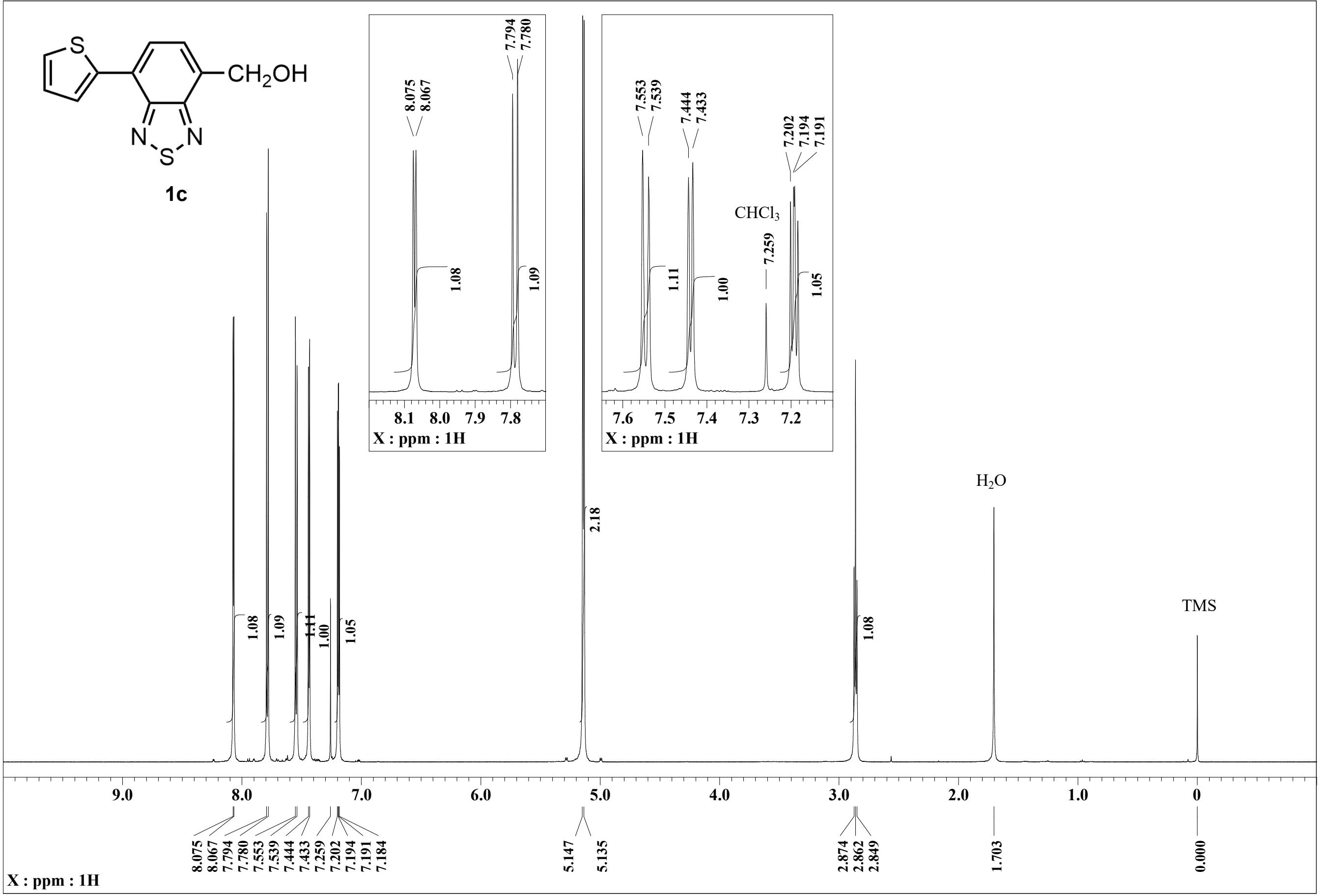


${ }^{13} \mathrm{C}$ NMR spectrum of $1 \mathrm{c}\left(126 \mathrm{MHz}, \mathrm{CDCl}_{3}, \mathrm{rt}\right)$

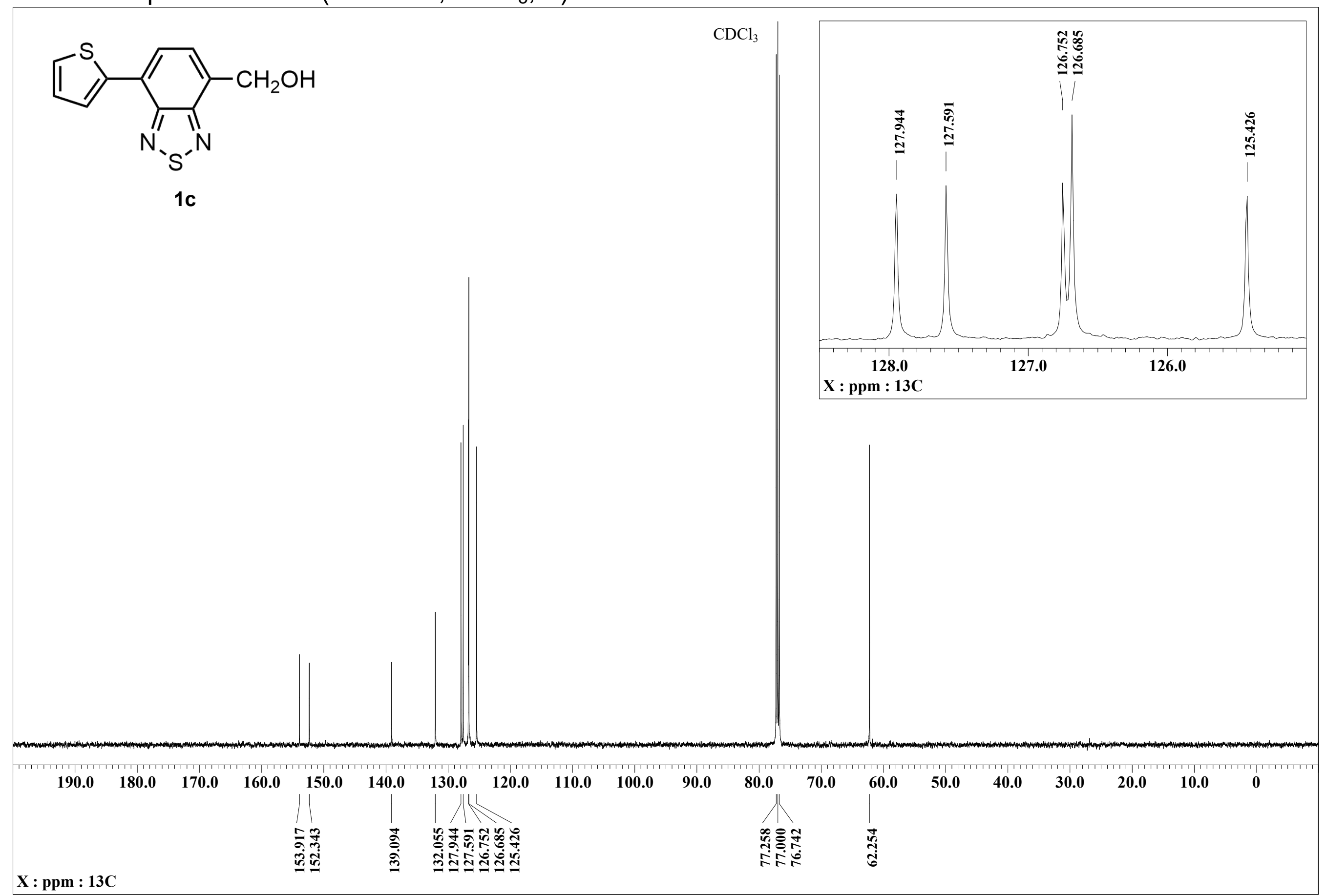


${ }^{1} \mathrm{H}$ NMR spectrum of $1 \mathbf{d}\left(500 \mathrm{MHz}, \mathrm{CDCl}_{3}, \mathrm{rt}\right)$

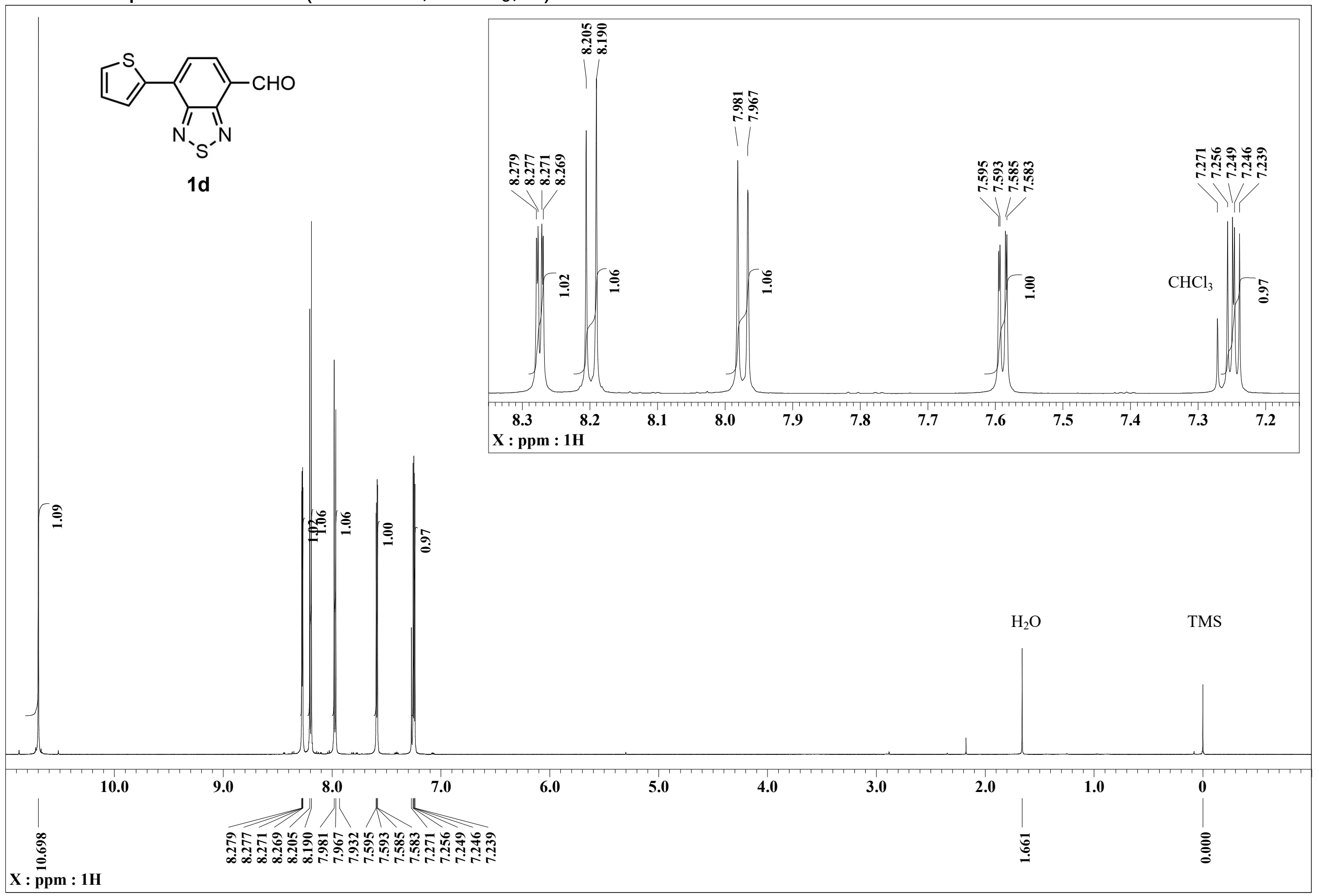


${ }^{13} \mathrm{C}$ NMR spectrum of $1 \mathbf{d}\left(126 \mathrm{MHz}, \mathrm{CDCl}_{3}, \mathrm{rt}\right)$

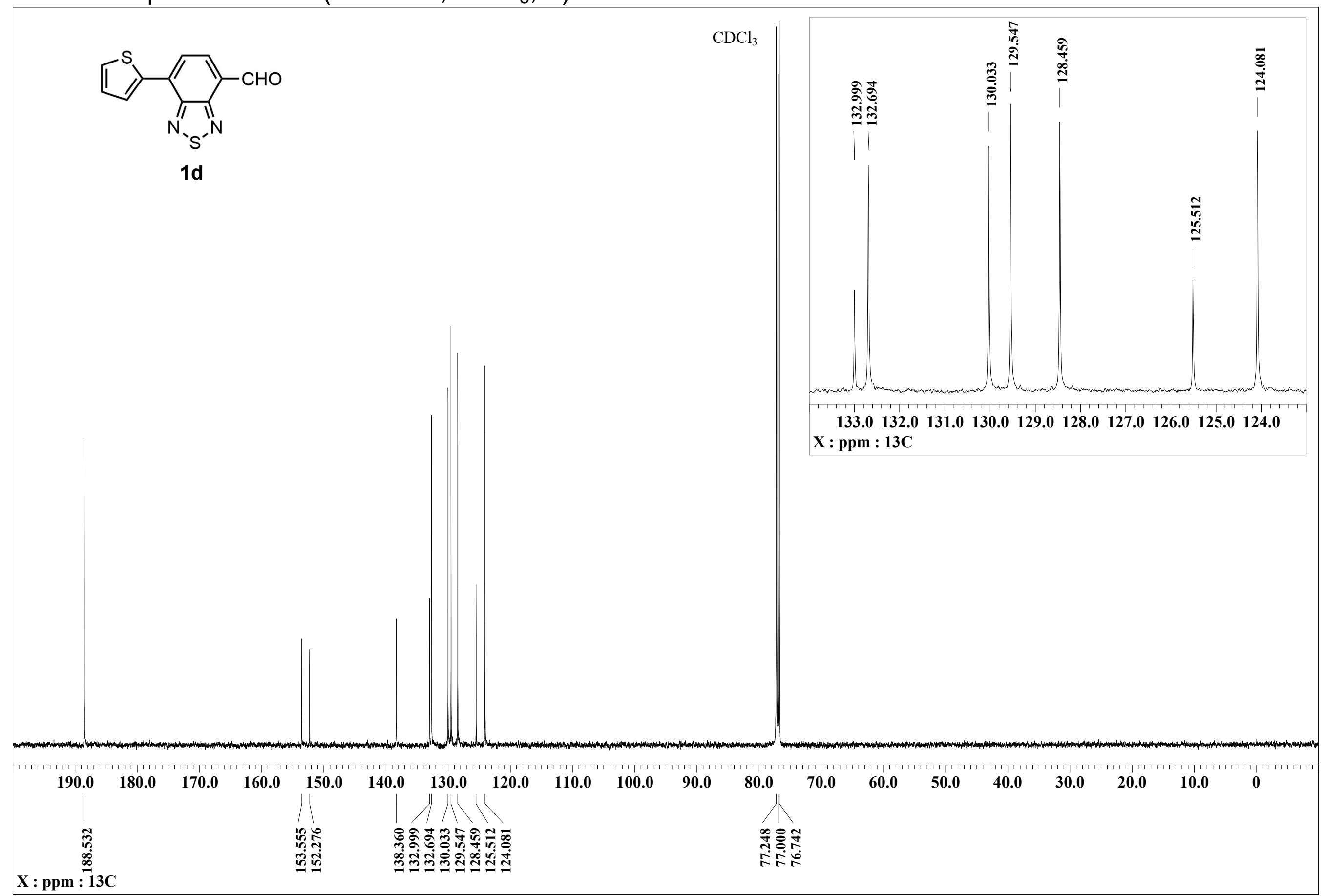


${ }^{1} \mathrm{H}$ NMR spectrum of $1 \mathrm{e}\left(500 \mathrm{MHz}, \mathrm{CDCl}_{3}, \mathrm{rt}\right)$

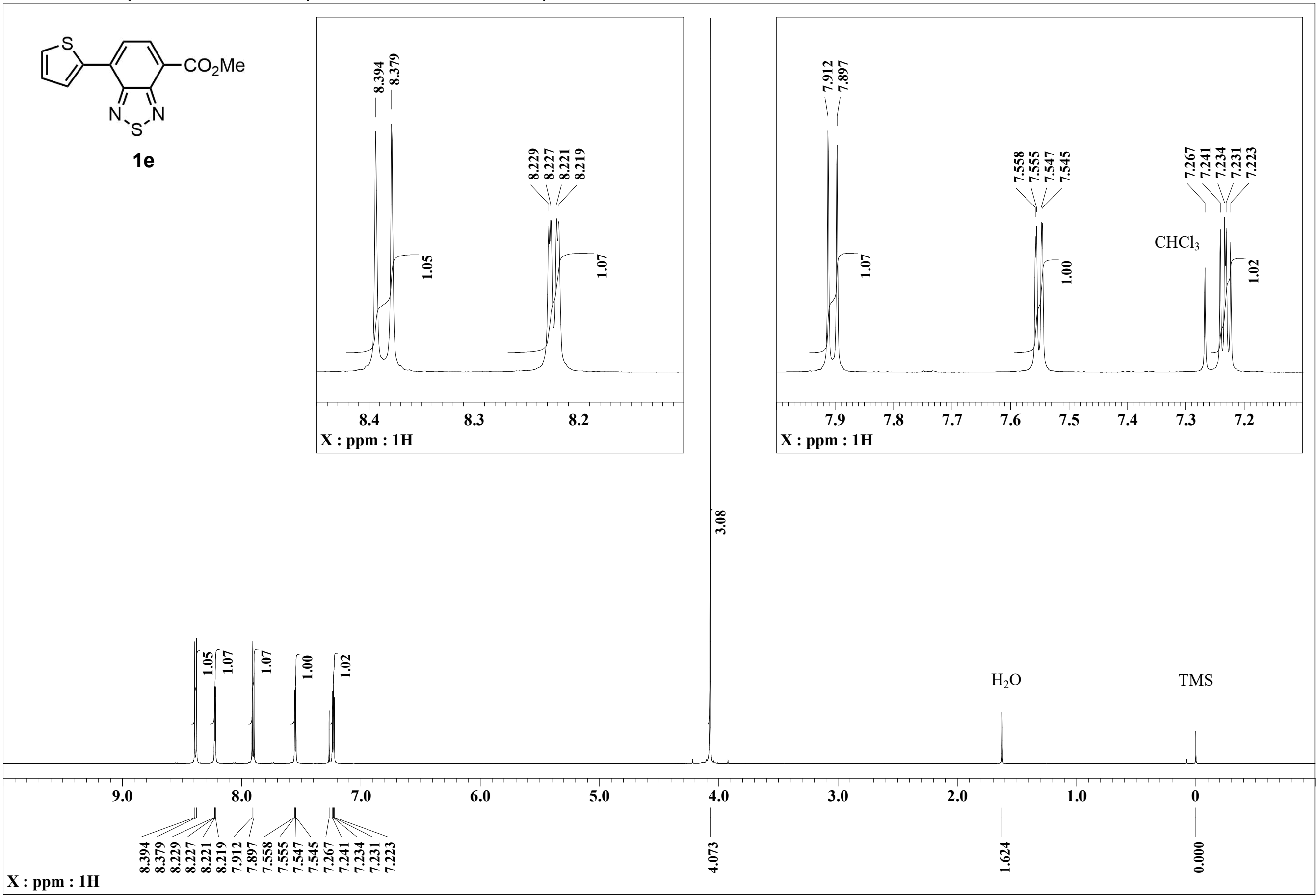


${ }^{13} \mathrm{C}$ NMR spectrum of $1 \mathrm{e}\left(126 \mathrm{MHz}, \mathrm{CDCl}_{3}, \mathrm{rt}\right)$

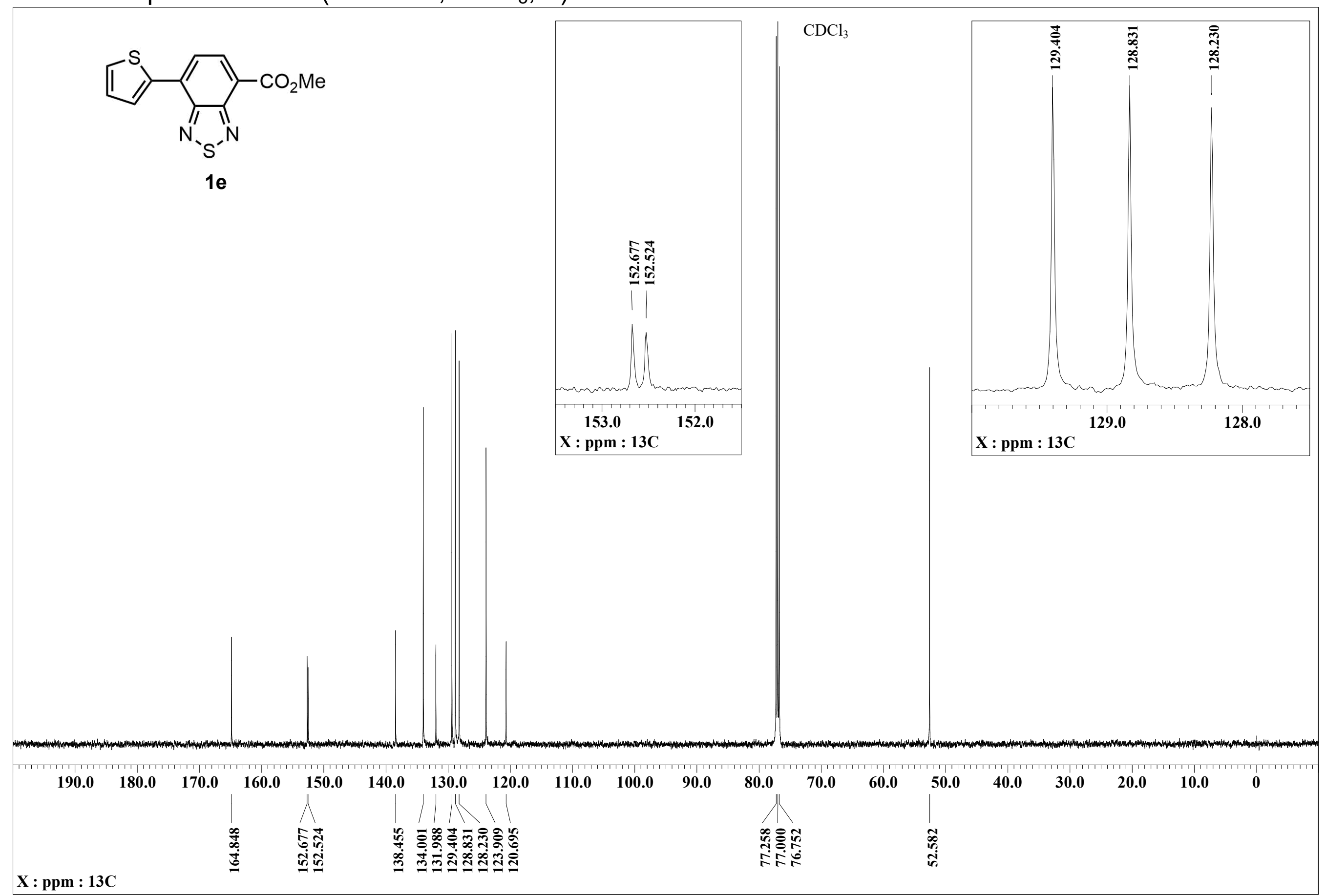


${ }^{1} \mathrm{H}$ NMR spectrum of $1 \mathrm{f}\left(500 \mathrm{MHz}, \mathrm{CDCl}_{3}, \mathrm{rt}\right)$

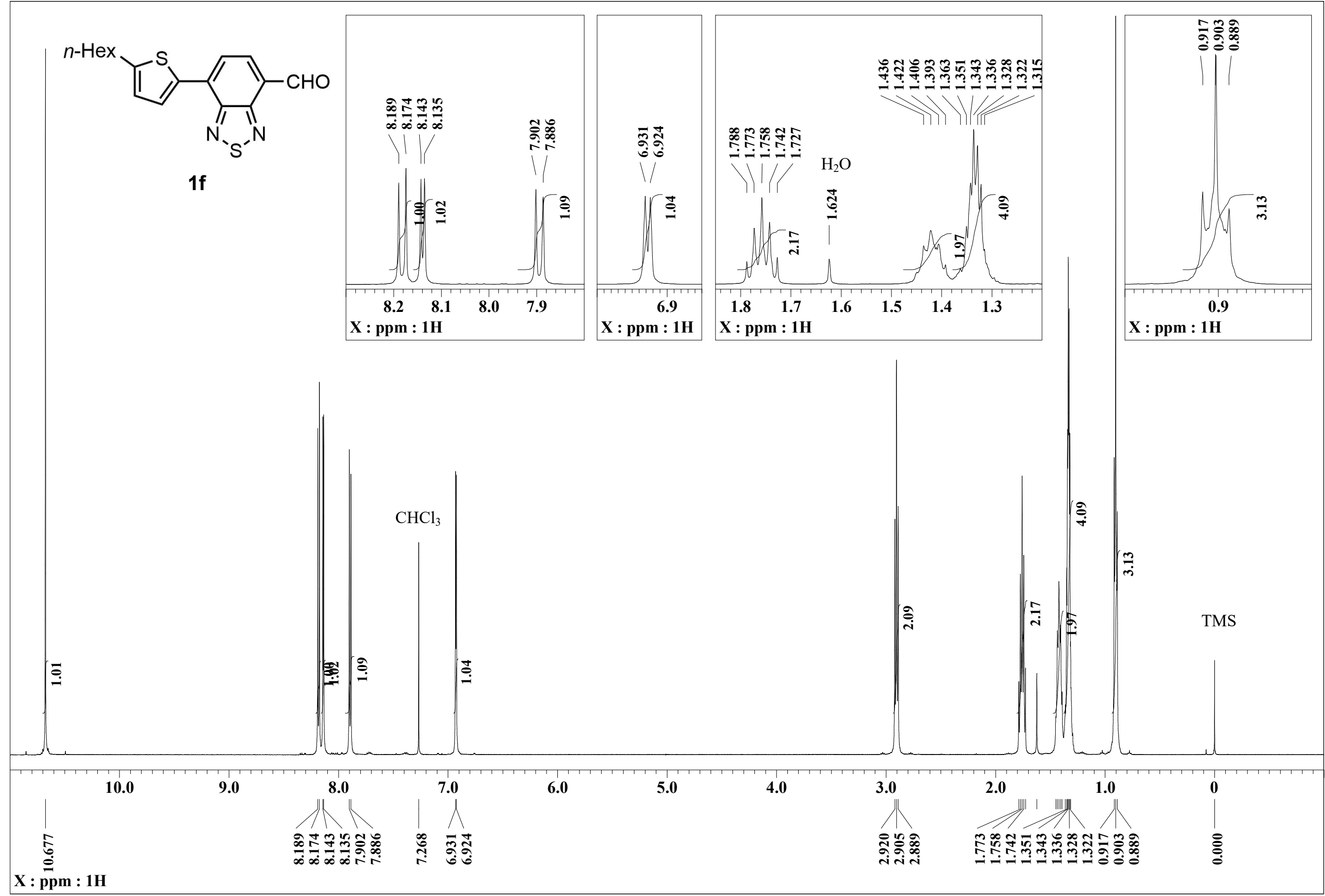


${ }^{13} \mathrm{C}$ NMR spectrum of $1 \mathrm{f}\left(126 \mathrm{MHz}, \mathrm{CDCl}_{3}, \mathrm{rt}\right)$

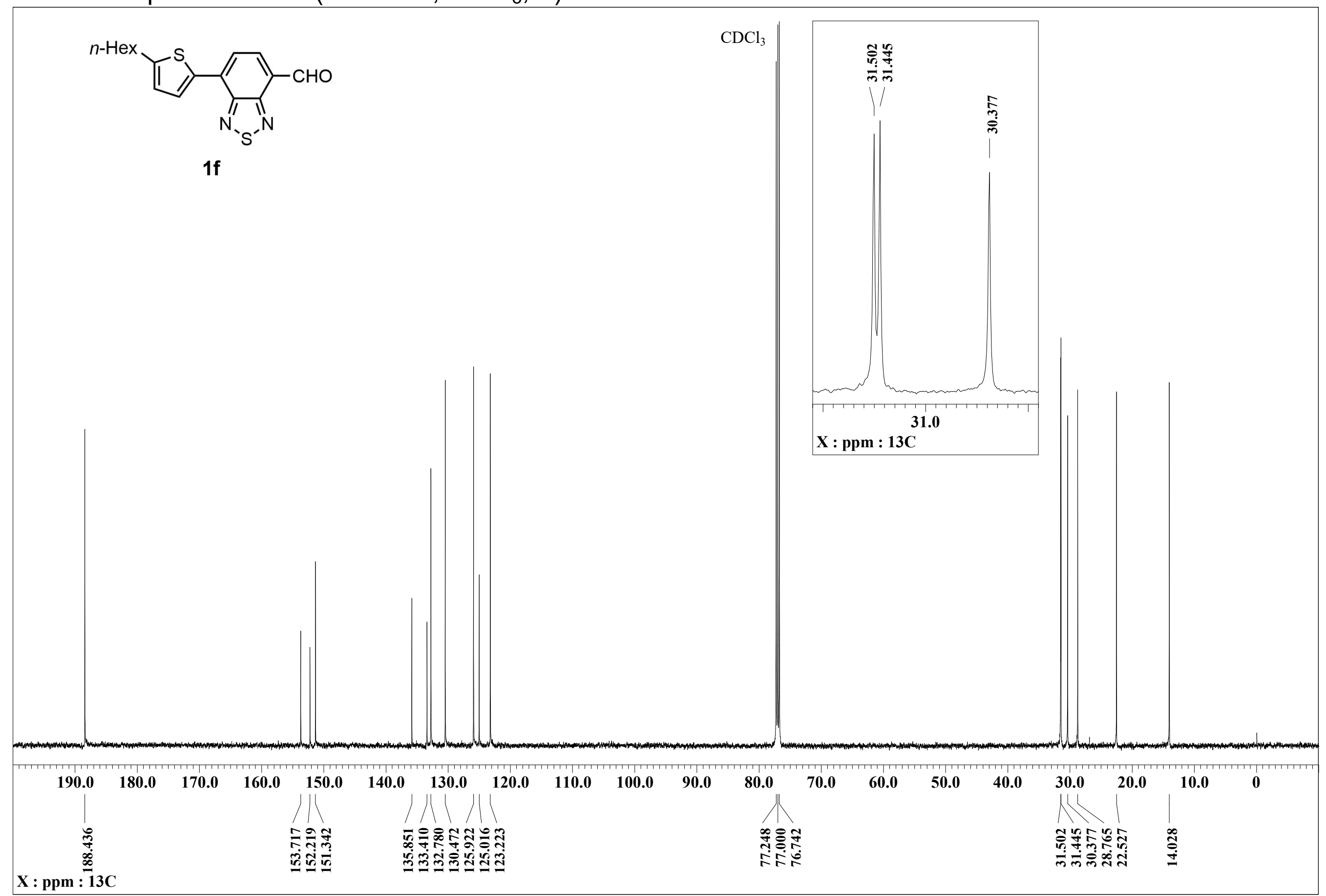


${ }^{1} \mathrm{H}$ NMR spectrum of $1 \mathbf{g}\left(500 \mathrm{MHz}, \mathrm{CDCl}_{3}, \mathrm{rt}\right)$

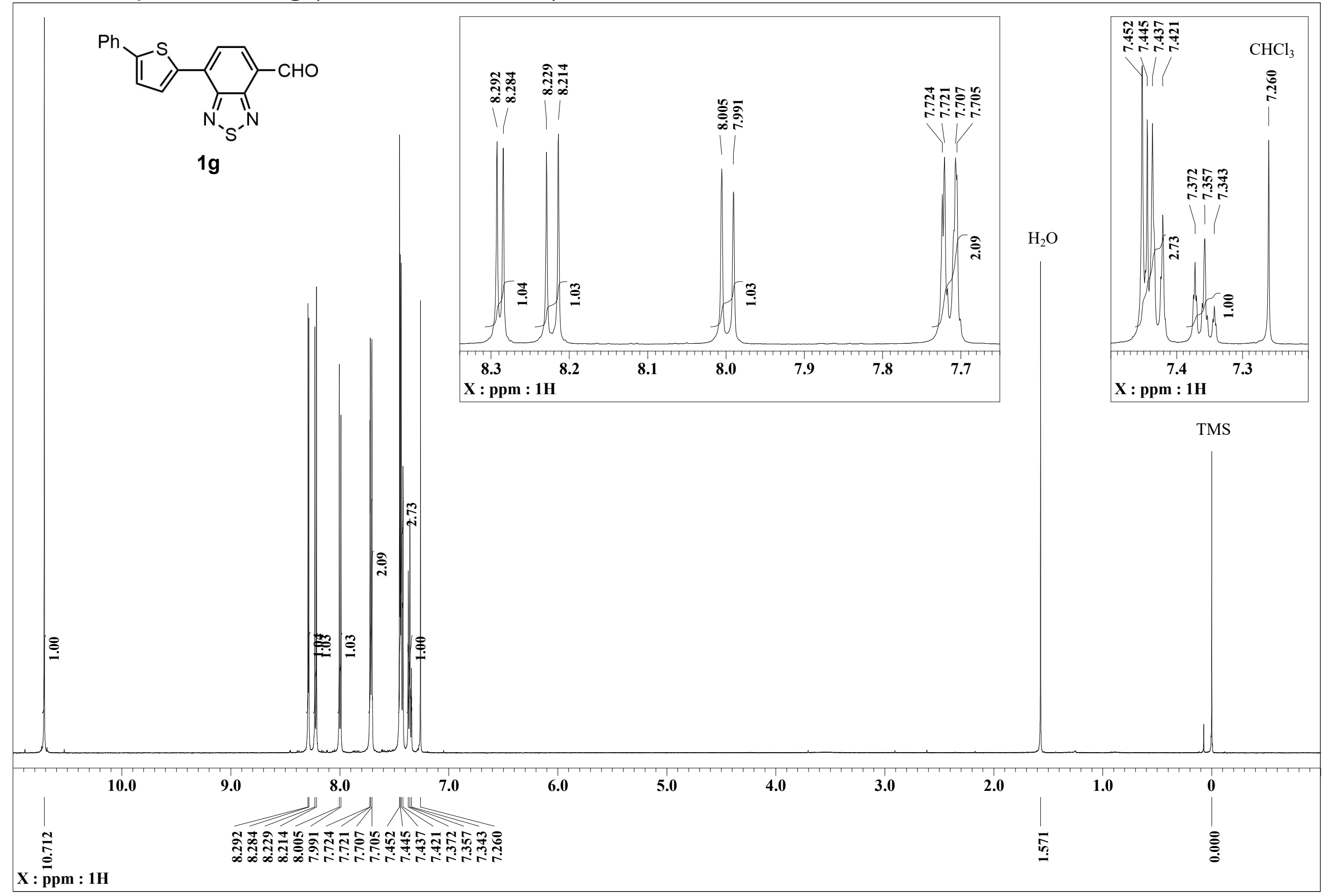


${ }^{13} \mathrm{C}$ NMR spectrum of $1 \mathbf{g}\left(126 \mathrm{MHz}, \mathrm{CDCl}_{3}, \mathrm{rt}\right)$

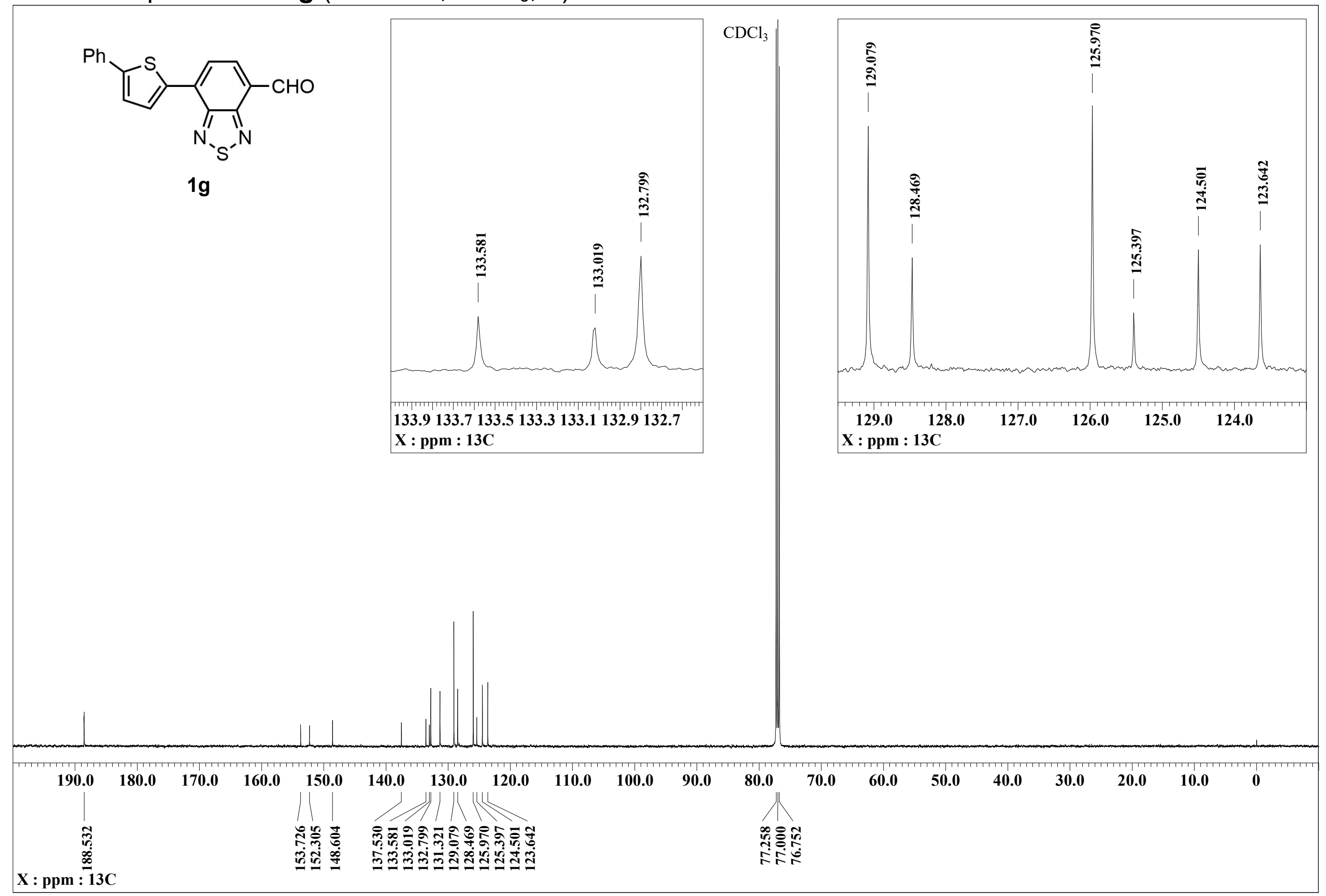

